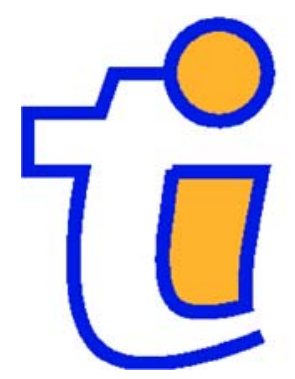

TI 2005-039/3

Tinbergen Institute Discussion Paper

Assessing the Value of Museums with a Combined Discrete Choice / Count Data Model

Jan Rouwendall

Jaap Boter ${ }^{2}$

${ }^{\prime}$ Department of Spatial Economics, Vrije Universiteit Amsterdam, and Tinbergen Institute,

2 Department of Marketing, Vrije Universiteit Amsterdam. 


\section{Tinbergen Institute}

The Tinbergen Institute is the institute for economic research of the Erasmus Universiteit Rotterdam, Universiteit van Amsterdam, and Vrije Universiteit Amsterdam.

Tinbergen Institute Amsterdam

Roetersstraat 31

1018 WB Amsterdam

The Netherlands

Tel.: $\quad+31(0) 205513500$

Fax: $\quad+31(0) 205513555$

Tinbergen Institute Rotterdam

Burg. Oudlaan 50

3062 PA Rotterdam

The Netherlands

Tel.: $\quad+31(0) 104088900$

Fax: $\quad+31(0) 104089031$

Please send questions and/or remarks of nonscientific nature to driessen@tinbergen.nl.

Most TI discussion papers can be downloaded at http://www.tinbergen.nl. 


\title{
Assessing the value of museums with a combined discrete choice / count data model
}

\author{
Jan Rouwendal and Jaap Boter \\ Department of Spatial Economics and Department of Marketing \\ Vrije Universiteit Amsterdam \\ De Boelelaan 1105 \\ $1081 \mathrm{HV}$ Amsterdam \\ Netherlands
}

This version: March 21, 2005

Keywords: museums, travel cost method, two stage budgeting

JEL Classification Codes: H41, D61, R53

\begin{abstract}
We develop a model for museum visits and estimate it on a large sample of holders of a museum card that provides free access to all museums. Our model distinguishes two stages, referring to the determination of the number of trips and destination choice and can deal with an effect of income on destination choice. We use a mixed logit model for destination choice and a count data model for explaining the number of trips. The model implies that welfare analyses should not only take into account the change in the logsum variables, but also changes in the number of trips. In our empirical application we find substantial local interest effects that cause a correlation between the attractiveness of a museum and its distance to the residential location of the visitor. The ranking of museums on the basis of their estimated attractiveness differs substantially from that based on the change in income that would be needed to compensate for its disappearance.
\end{abstract}





\section{Introduction}

Museums are generally regarded as an important feature of cities. For its inhabitants, they serve as a valuable amenity for cultural pursuits (Eurobarometer 2002; NEA 1998). The larger or 'Superstar' museums may even serve as magnets for attracting others, such as large crowds of tourists (Frey 1998). For instance, Bilbao, Spain, is known for its new Guggenheim Museum; The Louvre and Musée d'Orsay are important Parisian attractions; and the major tourist highlights of Amsterdam include the Van Gogh Museum, the Rijksmuseum with its large collection of Rembrandts and the Anne Frank House. Although highly appreciated by the public at large, many museums would be unable to survive in an open market. Admission fees, if charged at all, rarely cover operational costs. As the arts are considered to have important positive external effects for both the current society as well as future generations (e.g., Frey 2003), most museums receive government funding. Particularly in the last few years, a number of studies have tried to determine the appropriate level of government funding of museums by investigating their economic value (see Navrud and Ready 2002 for an overview). Rationale is that public funding of a cultural organization or object is justified as long as it does not exceed its economic value. ${ }^{1}$

In economics, travel costs are a familiar basis for inferences on the value of location-specific services. The so-called 'travel cost method' was suggested by Hotelling in a letter in 1947. It was further developed in the 1950s and 1960s by Clawson (1959) and Clawson and Knetsch (1966), among others. It estimates a demand function for a particular recreational site by considering the travel costs as the appropriate price for a visit. The empirical demand function may then be used as the basis for welfare calculations. Initially, the method was applied to single sites, but economic analysis of discrete choice, developed in the 1970s by McFadden $(1974,1981)$, opened up the possibility to analyze the choice for a particular destination among many possible ones. The discrete choice approach also tended to focus attention on individual behavior. Since the standard framework concerned individual decision-making with respect to a single trip, it was somewhat problematic to deal with households making multiple trips. However, in 1995 Hausman, Leonard and McFadden (1995) proposed a model that covered trip generation as well as destination choice in a single utility maximizing framework, using the two stage budgeting procedure of Strotz (1957) and Gorman (1959).

The use of travel-cost based procedures to determine the value of cultural institutions or objects has been limited. There have been three applications of demand functions based on travel costs. Forrest, Grime and Woods (2000), and Poor and Smith (2004) show that the use value of, respectively, a local theater and a heritage site alone exceed public funding. Martin (1994) uses travel costs as part of assessing the overall value of a local museum, whereby non use value is determined through Contingency Valuation. Rather than determining the value of a single cultural institution or site, Boter, Rouwendal and Wedel (2005) show how multiple museums may be compared by the different willingness to travel of their visitors. Their approach, however only uses information on destination choice. Heterogeneity among consumers is taken into account by means of five latent classes of consumers and there is no welfare analysis, only a comparison of the estimated attractiveness of the museums.

Similar to Hausman, Leonard and McFadden (1995), we use a logit model for destination choice and integrate it with a count data model for the number of trips. However, whereas the model of Hausman, Leonard and McFadden (1995) is based on separability of the direct utility function,

\footnotetext{
${ }^{1}$ A recent survey of the economics of museums is provided by Frey and Meier (2003).
} 
we propose an alternative approach, based on separability of the indirect utility function. This alternative procedure provides a theoretical motivation for the dichotomy between trip generation and destination choice, which is common in transportation analysis. Moreover, it avoids a difficulty associated with the method of Hausman, Leonard and McFadden that will be discussed more in depth later.

The model that we develop is consistent with the determination of the number of trips and destination choice as two stages in a utility maximizing planning procedure. We start with estimating the submodel that explains destination choice and use the results in estimating the count data model for trip generation. Our mixed logit destination choice model implies that the logsum, which is the welfare indicator related to destination choice, is a random variable. Since the logsum plays a role in the count data model, this randomness will be taken into account in estimating the latter model. In our approach the value of a museum is not completely determined by the (expected) change in the logsum variable multiplied by the observed number of museum visits. The total change in welfare is determined by the utility function that generates both the number of trips and their destinations. This change is a nonlinear function of the change in the logsum.

\section{The model}

Museum visiting behavior has at least two aspects: how many trips to make and which museum to visit on each trip. In transportation analysis these two aspects are often described as trip generation and trip distribution, respectively, and the two tend to be studied relatively independent of each other. The separation between these two aspects is more or less analogous to the two stage budgeting procedure in applied consumer theory. Two-stage budgeting allows a researcher to study the determination of the budget for expenditure on a group of commodities (for instance, those to be bought during a particular period) separately from the way this budget is distributed over particular commodities. It was studied first by Strotz (1957) and Gorman (1959) and makes use of the notion of (weak) separability in the utility function of the household. Conventional applications concern commodities that are available in continuous quantities, but Hausman, Leonard and McFadden (1995) recently employed it also for a discrete commodity, viz. the number of visits to recreational sites. In the present section we will discuss their method, point out a difficulty associated with it and develop an alternative approach that is based on the notion of indirect separability, i.e. weak separability of the indirect utility function.

In the first step of our procedure, which concerns trip generation, the total number of museum visits is determined on the basis of an indirect utility function. The arguments of this function are the prices of all other commodities than museum visits, total consumption expenditure and a scalar whose value is determined by the prices of museum visits. In the second step the distribution of the total number of visits over individual museum is determined on the basis of the prices of these visits.

\subsection{The method of Hausman, Leonard and McFadden}

Hausman, Leonard and McFadden (1995), which will be referred to from now on as HLM, propose a two-stage procedure that starts from a direct utility function in which a group of goods is separable from all other goods. In the present context, the relevant group would be museum visits, to be denoted with a suffix $M$. This function can be written as:

$u=u\left(x, U_{M}(q)\right)$ 
where $u$ denotes total utility, $x$ the vector of all other commodities than museum visits and $U$ the group utility function referring to such visits. This function is maximized under a budget constraint:

$$
p x+\pi q=y \text {. }
$$

where $p$ denotes the prices of other commodities, $\pi$ the prices of museum visits and $y$ the consumer's budget.

HLM assume that the indirect group utility function corresponding to $U_{M}$ satisfies the Gorman polar form:

$$
V_{M}\left(y_{M}, \pi\right)=\frac{y_{M}}{b(\pi)}+a(\pi)
$$

with $a(\pi)$ a constant. This implies that the indirect group utility function is homothetic and that the second term on the right hand side of (3) can be ignored. ${ }^{2}$ In this case $b$ can be interpreted as the price of an aggregate commodity. The number of units bought of this commodity is $y_{M} / b=q_{M}$. This means that we can substitute $q_{M}$ for $U_{M}(q)$ in the direct utility function and replace $y_{M}(=\pi q)$ in the budget constraint by $b q_{M}$. The first stage of the utility maximization procedure is the maximization of the rewritten function $u$ by choosing $x$ and $q_{M}$ under the rewritten budget constraint.

What remains is a consideration of the second stage of the budgeting procedure and here a difficulty arises. HLM specify $b$ as:

$$
b(\pi)=\ln \left(\exp \left(\gamma \pi_{i}\right)\right) / \gamma \text {. }
$$

The indirect utility function $V_{M}$ is the result of maximization of the group utility function $U_{M}$ subject to the constraint $\pi q=y_{M}$. It must therefore be homogeneous of degree 0 in the prices $\pi$ and the group budget $y_{M}$. This implies that the function $b(\pi)$ must be homogeneous of degree 1 in the prices. However, the specification suggested by HLM does not satisfy this requirement. If all prices are multiplied by $k$, we get: $b(k \pi)=\ln \left(\exp \left(\gamma k \pi_{i}\right)\right) / \gamma \neq k b(\pi)$. It must therefore be concluded that the method proposed by HLM is unsatisfactory. ${ }^{3}$

Furthermore, HLM also seem to be confused by the fact that $q_{M}$, the number of units of the aggregate commodity is not necessarily equal to the number of units bought from the individual commodities in the group $M$. Taking the specification for $V_{M}$ with the 'logsum' formula for $b$ as it stands, HLM derive the demand trips to destination $i$ correctly as:

$$
q_{i}=y_{M} \frac{e^{\gamma \pi_{i}}}{\sum_{j} e^{\gamma \pi_{j}}}
$$

and state that this is equal to the product of the total number of trips and the probability that a given trip has museum $i$ as its destination. (Note, by the way, that this equation is also clearly not

\footnotetext{
${ }^{2}$ When $a$ does not depend on the prices $\pi$, the direct group utility function $U_{M}$ can be written as $U_{M}=U^{*}(q)+a$, and $a$ 1 can be incorporated in the function $u$.

${ }^{3}$ Note that it doesn't help to interpret $\pi$ as a vector of real prices (that result, for instance, after dividing through a numéraire). In that case $y_{M}$ must be interpreted as the real budget for museum trips. Maximization of the group utility function under the group budget constraint then implies that indirect group utility is homogeneous of degree 0 in the real prices of museum visits and the real budget. The functions b should therefore be homogeneous of degree 1 in the real prices.
} 
homogeneous of degree 0 in $\pi$ and $y_{M}$ as it should be.) However, equation (5) shows that the total number of trips to museums $Q=\sum_{i} q_{i}$ is equal to $y_{M}$, but not to $q_{M}=y_{M} / b(\pi)$, as stated by HLM. ${ }^{4}$

A major attractive feature of the method proposed by HLM is that it combines a discrete choice (logit) and a count data model in a single utility maximizing framework. However, the previous discussion shows that there are difficulties associated with their procedure. In the remainder of this section we will discuss an alternative procedure, based on indirect separability, that avoids the inconsistencies and that leads to an empirical model that is otherwise similar to the one proposed by HLM.

\subsection{An alternative two-stage procedure}

We consider a consumer who derives utility from visiting museums and other consumption goods. His indirect utility function $v$ is:

$v=v(y, \pi, p)$

where, as before, $y$ denotes income, $\pi$ the prices of visiting museums and $p$ the prices of other consumer goods. The prices for visiting museums should be interpreted as the sum of the ticket price and the generalized travel cost. The indirect utility function is homogeneous of degree 0 in all prices and the consumption budget and we use one of the other consumption goods as the numéraire and interpret all prices and the budget as real variables.

We assume that $v$ satisfies the indirectly separable form: ${ }^{5}$

$v=v^{\prime}(y, p, w) \quad$ with $w=w(\pi, y)$

The demand $q_{i}$ for trips to a particular museum $i$ can be derived from (7) by means of Roy's identity:

$$
q_{i}=\frac{\frac{\partial v^{\prime}}{\partial \pi_{i}}}{\frac{\partial v^{\prime}}{\partial y}+\frac{\partial v^{\prime}}{\partial w} \frac{\partial w}{\partial y}}=\frac{\frac{\partial v^{\prime}}{\partial w} \frac{\partial w}{\partial \pi_{i}}}{\frac{\partial v^{\prime}}{\partial y}+\frac{\partial v^{\prime}}{\partial w} \frac{\partial w}{\partial y}}
$$

Total demand $Q$ for trips to museums is then equal to:

$Q=\frac{\partial v^{\prime} / \partial w}{d v^{\prime} / d y} \sum_{i} \frac{\partial w}{\partial \pi_{i}}$

where $d v / d y=\partial v^{\prime} / \partial y++\left(\partial v^{\prime} / \partial w\right)(\partial w / \partial y)$.

We now define the share of trips $s_{i}$ to museum $i$ in the total number of trips to museums as:

$s_{i}=\frac{q_{i}}{Q}=\frac{\partial w / \partial \pi_{i}}{\sum_{j} \partial w / \partial \pi_{j}}$

where $s_{i}$ denotes the share of trips to museum $i$ in the total demand for museum visits.

Equation (10) shows that the distribution of the total number of trips over the various museums is determined solely by the function $w$. Moreover, it shows that the distribution of the total number of trips over the museums depends only on the real prices of museum visits, not on the prices of other goods. This is a well-known consequence of implicit separability (see Blackorby et al., 1978). The distribution of the trips over the various museums can be regarded as the second stage

\footnotetext{
${ }^{4} q_{M}$ is their variable $T$ defined above their equation (2.3.6).

5 See Blackorby, Primont and Russel (1978) for a discussion of indirect separability.
} 
of a two stage procedure in which the number of trips is determined first, whereas the destinations are determined in the second stage, conditional on that number.

Such a two-stage procedure is especially useful if the choice in the first stage can be made on the basis of aggregate information about the alternatives in the second stage. This is the case if the trip generation process is independent of the specification of $\pi$. In order to guarantee this, we add two conditions:

$w(\pi, y)=w^{\prime}(\pi)$

$\sum_{i} \frac{\partial w}{\partial \pi_{i}}=1$

These two equations imply that (9) can be rewritten as:

$Q=\frac{\partial v^{\prime} / \partial w^{\prime}}{\partial v^{\prime} / \partial y}$

and this shows that the number of trips is determined by the function $v^{\prime}$, independent of the specification of the function $w^{\prime}$, even though it depends on the value of the variable $w^{\prime}$. Equation (11) requires that the function $w$ should be independent of total consumption expenditure $y$.

If these conditions are satisfied, the consumer is able to determine the optimal number of museum visits on the basis of information about income $y$, prices of other goods $p$ and the value of the function $w$, which gives a summary measure of the attractiveness of museums. In the second stage, the consumer determines the destination of the trips to be made on the basis of the associated prices for the visits $\pi$ and the number of trips $Q$, determined in the first stage. The procedure is analogous to that of Strotz and Gorman, which is based on direct separability. The role that the budget (for museum trips in the present context) plays in their procedure is replaced by that of the number of trips in the procedure proposed here, which is based on indirect separability.

In order to interpret (12), it may be noted that it implies that $\exp \left(w^{\prime}\right)$ must be homogeneous of degree 1 in the exponentiated prices $e^{\pi_{i}}$. Any homogeneous-of-degree-1 function $f(x)$ can therefore be used as a starting point for specification of the function $w^{\prime}$. A convenient choice is the 'ces' specification $f(x)=\left(\sum_{i} x^{\beta}\right)^{1 / \beta}$ which leads to the 'logsum' formula:

$$
w^{\prime}(\pi)=\frac{1}{\beta} \ln \left(\sum_{i} e^{-\beta \pi_{i}}\right)
$$

This means that the present framework allows us to use the logit specification for destination choice.

Equation (14) suggests that we can regard $w^{\prime}$ as some average price of museum visits. It must, however, be noted that $w^{\prime}$ does not have all the usual characteristics of a price index. For instance, (12) rules out the possibility that $w^{\prime}$ is homogeneous of degree 1 in the prices $\pi$. Note, however, that this type of homogeneity is not necessarily a desirable property of $w^{\prime}$, as it would imply that a proportional increase in the (real) prices of all museums would have no effect on the distribution of museum trips. One would expect substitution towards relatively cheap destinations in this situation and this is consistent with the formulation found here. The homogeneity of $\exp \left(w^{\prime}\right)$ in the exponentiated prices implies that a change of all prices with the same amount $z$ would change $w^{\prime}$ by a factor $\ln (z)$ and would leave the trip distribution unchanged. 
The previous discussion implies that the proposed two-stage procedure imposes some constraints on the specification of destination choice for museum trips. Note, though, that in this respect there is no difference with the procedure suggested by HLM, since they use the same functional forms as proposed here. Moreover, at the end of the present section we will discuss the consequences of relaxing condition (11).

\subsection{Other specification issues}

The previous subsection outlined a two-stage budgeting procedure based on indirect separability. The present one is concerned with the specification of an estimable model for museum trips that fits within this framework. Since we want to use a count data model for explaining the number of visits (trip generation), it is convenient to choose a specification of the utility function that leads to a demand function that is log-linear in the explanatory variables $y$ and $w^{\prime}$ :

$v^{\prime}=\frac{y^{1-\alpha}}{1-\alpha}-\frac{1}{\eta} e^{\gamma+\eta w^{\prime}}$

Application of 'Roy's identity' to (15) gives:

$Q=\exp \left(\gamma+\eta w^{\prime}+\alpha \ln (y)\right)$.

In economic geography and transportation it is common to relate trip generation to accessibility measures. Such measures indicate how close economic actors are to potential destinations for spatial interactions. They may be made specific for special trip purposes such as shopping or recreation. The practice of using such measures in other fields suggests that it may be useful to relate museum visits also to an accessibility measure.

Accessibility is usually defined as a weighted average of the attractiveness of the various possible destinations, where the weights are some function of the generalized travel costs. Since these costs are related to the distance to be traveled, this function is known as the distance decay function. We interpret the generalized travel costs as the prices for museum visits and define accessibility of museums as:

$$
A(\pi)=\sum_{i} A_{i} f\left(\pi_{i}\right)
$$

The attractiveness of a particular museum for a potential visitor depends on the characteristics of the museum. Note that the travel costs are dependent on the location of the traveler and that accessibility is therefore location-specific.

The function $f$ is usually specified as a power function or an exponential function. Adopting the latter possibility, we define:

$f\left(\pi_{i}\right)=\exp \left(-\beta \pi_{i}\right)$

The function $w^{\prime}$ is now defined as the logarithm of this accessibility function, divided by $\beta$ :

$$
w^{\prime}=-\frac{1}{\beta} \ln \left(\sum_{i} A_{i} e^{-\beta \pi_{i}}\right)
$$

It is readily verified that this function does not have the consumer's total expenditure level as an argument and that it satisfies (12). Use of this function is therefore consistent with the two-stage procedure discussed above. The interpretation of $w^{\prime}$ as a price is easier to appreciate if we rewrite (3) as: 


$$
\begin{aligned}
w^{\prime} & =-\frac{1}{\beta} \ln \left(\frac{\sum_{i} A_{i} e^{-\beta \pi_{i}}}{\sum_{i} A_{i}}\right)+\frac{1}{\beta} \ln \left(\sum_{i} A_{i}\right) \\
& =\pi^{*}-\frac{1}{\beta} \ln \left(\sum_{i} A_{i}\right)
\end{aligned}
$$

The first term between brackets on the right-hand-side is a weighted average of the exponentiated prices of museum visits that have been raised to the power $\beta$. Its logarithm can, after division through $\beta$, be interpreted as a kind of average price, denoted here as $\pi^{*}$. Indeed, the price $\pi^{*}$ is between the lowest and the highest price of the museums: $\min _{i}\left\{\pi_{i}\right\} \leq \pi^{*} \leq \max _{i}\left\{\pi_{i}\right\}$. The second term on the right hand-side of (20) can be interpreted as the quality aspect of museums. A higher quality as the same effect as a lower price. ${ }^{6}$

For given values of the attractiveness of museums, the second term on the right hand side of (20) may be interpreted as reflecting quality aspects of museum visits.

The equations for trip distribution that follow from (19) are:

$s_{i}=\frac{A_{i} e^{\beta \pi_{i}}}{\sum_{j} A_{j} e^{\beta \pi_{j}}}$

They can be rewritten in more familiar 'logit' form using the identity $A_{i}=e^{\ln A_{i}}$.

\subsection{Welfare economic analysis}

What are the implications of this model with respect to the value of museums? In order to answer this question, we consider the marginal effect of a change in the value of the price $\pi_{i}$ of museum $i$. We take the indirect utility function (7), with conditions (11) and (12) imposed as our starting point. The change in income needed to compensate for the price change is:

$d y=-\left(\frac{\partial v^{\prime}}{\partial w^{\prime}} / \frac{\partial v^{\prime}}{\partial y}\right) \frac{\partial w^{\prime}}{\partial \pi_{i}} d \pi_{i}$.

The term between brackets on the right hand side is related to trip generation, the second to destination choice. When equation (19) is used for the composite price $w^{\prime}$, this second term is the change in the 'logsum'. The change in the logsum is therefore only equal to the total effect if the price change when $\partial v^{\prime} / \partial w^{\prime}=1$. This condition is fulfilled for the indirect utility function:

$v^{\prime}=\frac{y-w^{\prime}}{b}$.

It may be noticed that (23) gives the utility which can be interpreted as referring to an individual who represents a population of consumers with random utility functions that correspond to the logit model (cf. McFadden, 1981). ${ }^{7}$ Application of (13) shows that the total number of trips $Q$ is always equal to 1 when indirect utility is given by (23).

If we did not have information about the number of visits undertaken by a household, the evaluation of the museums can only be based on the change in the logsum variables. It is natural

\footnotetext{
${ }^{6}$ Note that the value of $w^{\prime}$ may be negative, even though the value of the price $\pi^{*}$ is positive whenever all $\pi_{i}$ s are positive.

${ }^{7}$ It may be noted that $w$ ' may be a function of the other prices $p$ as well as of the prices $\pi$ of the commodities belonging to the own group. We could also allow for this possibility in the model structure developed in section 2 .
} 
to proceed then by multiplying this change by the number of trips $Q$ that has been undertaken by the household. This assumes implicitly that the term between brackets on the right hand side of (22) is equal to $Q$. In the framework developed here, this is indeed the case (cf. (13)), but in general it is not true.

If one considers finite changes in the price $\pi_{i}$ multiplication of the change in the logsum variable by the observed number of trips requires the implicit assumption that the number of trips does not change as a consequence of this price change. This is only the case under restrictive specifications of the indirect utility. For instance, generalizing (23) to:

$$
v^{\prime}=\frac{y-Q w^{\prime}}{b} \text {. }
$$

with $Q$ a constant equal to the number of trips provides justification for this practice. However, if we adopt a utility function in which $\partial v^{\prime} / \partial w / \partial v^{\prime} / \partial y$ is not a constant, but a function of the composite price $w^{\prime}$ and income $y$, multiplication of the change in the logsum by the number of trips can only provide an approximation.

The monetary value to a consumer of being able to visit museum $i$ can be computed as follows. By letting $\pi_{i} \rightarrow \infty$ we can determine the value of $w^{\prime}$ that corresponds with the disappearance of museum $i$. Denoting the cost function associated with indirect utility function $v^{\prime}$ as $c$, we can then determine the value $V_{i}$ of museum $i$ as:

$V_{i}=c\left(v_{0}{ }^{\prime}, w_{0}{ }^{\prime}\right)-c\left(v_{0}{ }^{\prime}, w_{1}{ }^{\prime}\right)$

where suffix 0 denotes the situation with the actual trips cost $\pi_{i}$ and suffix 1 that with infinitely high trip cost for museum $i$. For utility function (15), which will be used in the empirical work below, this gives:

$V_{i}=y_{0}-\left(y_{0}^{\alpha+1}-\frac{\alpha+1}{\eta}\left(\exp \left(\gamma+\eta w_{0}{ }^{\prime}\right)-\exp \left(\gamma+\eta w_{1}{ }^{\prime}\right)\right)\right)^{1 /(\alpha+1)}$

This may differ substantially from the difference between the $\operatorname{logsums}\left(w_{0}{ }^{\prime}-w_{1}{ }^{\prime}\right)$.

Equation (26) gives the compensating variation of the loss of this museum to one particular visitor. Summation over all members of a group gives an indication of the value of the museum for such a group of consumers.

\subsection{Incorporating income effects in museum choice}

If museum choice is related to income, condition (11) is violated. Since it seems likely that preferences for museums are dependent on income, it is useful to consider the consequences of a relaxation of this condition. Suppose, therefore, that we drop (11), while maintaining (12). Total demand for museum trips then follows from (9) as:

$$
Q=\frac{\partial v^{\prime} / \partial w^{\prime}}{\partial v^{\prime} / \partial y+\left(\partial v^{\prime} / \partial w^{\prime}\right)\left(\partial w^{\prime} / \partial y\right)}
$$

This can be rewritten as:

$$
Q=\frac{Q^{*}}{1+Q^{*}(\partial w / \partial y)}
$$

where $Q^{*}=\left(\partial v^{\prime} / \partial w^{\prime}\right) /\left(\partial v^{\prime} / \partial y\right)$ denotes demand in case the composite price of museum visits were independent of income. If the composite price increases with income (for instance, because of a higher value of travel time), this has a decreasing effect on the number of trips. If the composite price decreases with income (for instance, because a consumer with a higher income appreciates 
some museums more) this has an increasing effect on the number of trips. In our empirical work we will generalize (19) by making both the attractiveness $A_{i}$ and the distance decay parameter $\beta$ dependent on income.

\section{Data and some econometric issues}

\subsection{Data}

The basis of our dataset is the transaction data of Dutch National Museum Card holders used by Boter, Rouwendal and Wedel (2005). This Museum Card is an important tool in promoting museum attendance in The Netherlands. In return for an annual fee of $€ 25$ for adults or $€ 12.50$ for anyone younger than 26 years, card holders get free access to 442 museums in this country; the only remaining cost per visit being the cost of traveling. At the 150 largest participating museums, card holder visits are logged electronically. These data are collected and stored on a central server to aid reimbursement to the museums. The dataset provided by the organization was limited to customer number, type of card (youth or adult), the museum, the date and time of the visit, and the zip codes of both museum and visitor. Using a commercial GIS database that contains travel distance and travel time by road for every zip code combination in The Netherlands, travel distance and travel time were added to the dataset for each recorded visit. Similar to Boter, Rouwendal and Wedel (2005), we only use the visits of one full year (2002) to exclude seasonal effects on demand. Also, museums with missing data or that faced incidental closure were excluded. The remaining 108 museums are a representative variety in size, type of collection and location.

In addition to the dataset of Boter, Rouwendal and Wedel (2005), we introduce two groups of additional variables. Firstly, we add eight dummy variables to indicate the kind of collections a museum offers. The eight collection categories were provided by the Dutch National Museum Association (NMV), who also carried out the consequent classification of the 108 museums and their collections. Secondly, we add the card holder's estimated income to the dataset. No personal data on income is registered in the transaction data. However, many public and commercial databases hold information on the average income per zip code. Here, we use public data from the Dutch Central Bureau of Statistics in which income is defined as "average total income in euros after tax per inhabitant". These numbers were provided by the Bureau per zip code.

\subsection{Some problems associated with applying the travel cost method}

The size of this dataset has the distinct advantage that it captures a wide range of different museums, locations, competitive situations and travel distances. On average, card holders made 4.3 visits to 3.3 of the 108 museums in our dataset. A preliminary analysis of the dataset reveals that within the common willingness to travel of 44.9 minutes, the average card holder has 29.5 out of the 108 museums to choose from. The museums visited are therefore likely to reflect a real utility to the card holder.

However, when applying the travel cost method to these data, some complications have to be taken into account. The model assumes that observed museum visits are the result of trips that have this visit as their single (or at least most important) purpose so that travel costs can indeed be regarded completely as (part of) the price of this visit. Moreover, it assumes that preferences for a particular museum are independent of the household's location. Both assumptions may be violated in our data, and in the present subsection we will examine the possible consequences. 
The first problem mentioned above occurs, for instance, when a household is on holiday for a number of days or weeks in a particular place and visits a museum as part of a larger program of recreational activities. It is the total program that made the holiday, including the museum visit, worthwhile, but it will generally be wrong in this situation to interpret the total travel cost from the household's residential location to the museum as an indication of their willingness to pay for the museum visit. The second problem occurs when a museum has a collection that is of special interest for the inhabitants of a particular town or region, for instance by concentrating on local history. In such a case it is likely that especially the inhabitants of that particular place or region are interested in the museum. Attractiveness of the museum is then correlated with a household's distance to the museum and hence with travel cost.

We deal with the first problem by eliminating from the data all museum visits that have been undertaken during school holiday periods. Admittedly, this procedure is somewhat crude, but given the limitations of the data it seems the best we can do to address the problem. In order to deal with the second one, attractiveness is re-specified as:

$A_{i}=A_{0 i} e^{a_{1 i} \pi_{i}}, \quad a_{1 i} \leq 0$.

This extended specification implies that the destination choice model (21) becomes:

$s_{i}=\frac{A_{0 i} e^{\beta_{i} \pi_{i}}}{\sum_{j} A_{0 j} e^{\beta_{i} \pi_{j}}}, \quad \beta_{i}=\beta+a_{1 i}$

The newly defined 'distance decay' coefficient is destination specific and will be smaller (in absolute value) than $\beta$ if there is a 'local interest' effect. One consequence of this extended specification is that $\beta$ the 'pure' distance decay parameter is no longer identified. We will return to this issue when discussing the estimation results.

\subsection{The trip distribution model}

It was noted in the theoretical section above that the model developed in this paper is

characterized by a distinction between trip generation and trip distribution. We will therefore start with a discussion of the latter and consider later how the distribution model fits into the remainder.

The model as it has been discussed until now refers to a single household. When estimating the model on data referring to different households, we have to face the possible heterogeneity in the population. Since it is clearly improbable that all consumers have the same preferences with respect to museums, we would like to allow the parameters of the model to vary over households. Since information about household characteristics is lacking, we will treat these parameters as random variables. The values that are relevant for a particular consumer $k$ are regarded as a random draw from the joint distribution of parameters. It is assumed that the same values of the parameters are relevant for all choices made by a given household. That is, individual preferences do not change. Since the sign of the attractiveness $A_{i}$ and the distance decay parameters $\beta$ is known a priori, we use the lognormal distribution. The simplest and most common way to proceed is to assume independence of all the random variables by setting all off-diagonal elements of the variance-covariance matrix equal to 0 . However, it seems likely that there is correlation between the attractiveness of some museums. For instance, if two museums have collections that are more or less similar (for instance, both concentrate on natural history or on paintings from the 17 th century) this is likely to be the case. 
In order to account for this effect, we use the classification of the museums in eight categories, which has been discussed above. We specify the attractiveness and the distance decay parameters as: ${ }^{8}$

$\beta_{k}=\beta_{0}+\sigma_{0} \varepsilon_{0 k}$,

$\ln \left(A_{i k}\right)=a_{0 i}+a_{i} \pi_{i k}+\sigma_{i} \varepsilon_{i k}+\sum_{l=1}^{8} d_{i, l} \rho_{l} \varphi_{l k}$

where the $\varepsilon_{i k}$ 's and $\varphi_{l k}$ 's are the independent drawings from the standard normal distribution for household $k$. (31a) states that the distance decay parameter is normal distributed with parameters $\beta_{0}$ and $\sigma_{0}$ respectively. (31b) states that the attractiveness of museums is multivariate lognormal distributed. The $d_{i, l}$ 's are dummies that are equal to 1 if museum $i$ belongs to class $l$ and 0 otherwise. Every museum, except one, belongs to a single class. The exception concerns a museum belonging to two classes. Two classes have only one member and for the museums belonging to these classes $\rho$ has been set equal to 0 . For these two cases the marginal distribution of attractiveness is lognormal with parameters $a_{0 \mathrm{i}}+a_{i} \pi_{i k}$ and $\sigma_{i}$. For the museums belonging to a category with more than one member, the attractiveness is lognormal with parameter values $a_{0 i}+a_{i} \pi_{i k}$ and $\left(\sigma_{i}+\rho_{l(i)}\right)$ where $l(i)$ denotes the class to which museum $i$ belongs. For the museum that belongs to two classes the obvious generalization of this expression is relevant. Since the researcher does not observe the actual parameter values, integration over the joint distribution should take place in the likelihood function.

The share $s_{i}$ of the trips made to museum $i$ in the total number of museum visits made by a particular consumer is given by the 'logit' formula in (30). This quantity share is equal to the probability that a trip made by this consumer has museum $i$ as its destination. This suggests the construction of the likelihood of observing a particular combination of museum trips by a consumer from these quantity shares. We have to estimate the parameters $a_{0 i}, \beta_{i}\left(=\beta_{0}+\alpha_{1 i}\right), \sigma_{i}$ and $\rho_{l}$. Since we cannot observe the drawings $\varepsilon$ and $\varphi$, we have to 'integrate out' these variables. The likelihood of the observed pattern of trips made by consumer $k$ is:

$l_{d}(k)=\iint_{\varepsilon} \prod_{\varphi}^{N(k)} s_{i(m, k)}\left(a_{0},\left(\beta_{0}+a_{1}\right), \sigma, \rho ; \varepsilon, \varphi\right) f(\varepsilon, \varphi) d \varepsilon d \varphi$

where $i(m, k)$ denotes the destination of the $m$-th trip made by consumer $k$ and $f$ is a product of standard normal density functions.

The model derived above is clearly similar to the mixed logit model of discrete choice theory although it has been derived in a different way. A discrete choice, or random utility model starts from a specification of the utilities of individual museums as the sum of a deterministic and a stochastic part. The latter is assumed to be Extreme Value type I distributed and this leads to the logit model. The mixed logit model arises if some or all coefficients of the logit model are considered to be random variables, irrespective of the way the logit model was derived.

The group structure implied by $(31 \mathrm{~b})$ is in some respects similar to that of the nested logit model of conventional discrete choice theory (see Train 2002, 159, for a discussion of the relationship between mixed logit and nested logit). Note, however, that the random coefficient formulation adopted here is better suited for repeated observations of trips by the same household than the nested logit model, since it allows one to link the correlation between the utilities of museums in a given group to individual effects in the preferences of the consumer. This is impossible in the standard version of the nested logit model.

${ }^{8} a_{0 i}=\ln \left(A_{0 i}\right)$ in the notation of (30). 
The museum choice model can be made income dependent by respecifying attractiveness and distance decay as:

$$
\begin{aligned}
& \beta_{k}=\beta_{0}+\beta_{1} y+\sigma_{0} \varepsilon_{0 k}, \\
& \ln \left(A_{i k}\right)=a_{0 i}+a_{1 i} \pi_{i k}+a_{2 i} \ln (y)+\sigma_{i} \varepsilon_{i k}+\sum_{l=1}^{8} d_{i, l} \rho_{l} \varphi_{l k} .
\end{aligned}
$$

Estimation proceeds in the same way as for the model without income effects.

\subsection{Trip generation model}

For trip generation we use the utility function (15). Since we found that destination choice is income-dependent, we have to derive the demand function (27). For the chosen utility function the predicted number of trips is given by:

$$
\ln (Q)=\gamma+\eta w^{\prime}+\alpha \ln (y)+\ln \left(1+\exp \left(\gamma+\eta w^{\prime}+\alpha \ln (y)\right) \frac{\partial w^{\prime}}{\partial y}\right) .
$$

with w' and its derivative with respect to income as implied by $(33 a, b)$.

We used the negative binomial model that gives the probability of observing $x$ trips as:

$$
f(x)=\frac{\Gamma\left(x+\lambda^{-1}\right)}{\Gamma\left(\lambda^{-1}\right) \Gamma(x+1)}(\lambda Q)^{x}(1+\lambda Q)^{-\left(x+\lambda^{-1}\right)}
$$

where $\Gamma($.) denotes the gamma function. This distribution has expectation $Q$. The parameter $\lambda$ reflects overdispersion in comparison with the Poisson distribution. The latter distribution has a variance that is equal to its expectation, which often rejected. When $\lambda \rightarrow 0$ the negative binomial model approaches the Poisson model (see, for instance, Cameron and Trivedi, 1998).

In estimating the model, we have to take into account that we only have information about households who visited at least one of the 108 museums during the observation period. This means that counts are truncated at the value zero. We should therefore use the conditional distribution $g(x)=f(x) /(1-f(0))$ as the basis for our likelihood function.

The likelihood is a function of the parameters $\gamma, \eta, \alpha$ and $\lambda$, which have to be estimated. One of the arguments of $Q$ is $w^{\prime}$, and this is a function of the parameters that have been estimated for the destination choice model and will here be taken as given. Moreover, $w^{\prime}$ is a function of the random variables $\varepsilon$ and $\varphi$ and therefore itself a random variable. We can deal with this issue by 'integrating out' these random variables. In doing so, we can make use of the information that the destination choices of a household gives us about the values of these random variables for a particular household $k$. This information can be taken into account by using the (posterior) probability of the observed sequence of destination choices for the particular values of the random variables when performing the integration (see Train, 2002, chapter 11, for a discussion of the method). The weights are determined as:

$$
w(k \mid \varepsilon, \varphi)=\frac{\prod_{m=1}^{N(k)} s_{i(m, k)}\left(a_{0},\left(\beta+a_{1}\right), \sigma, \rho ; \varepsilon, \varphi\right)}{\iint_{\varepsilon} \prod_{m=1}^{N(k)} s_{i(m, k)}\left(a_{0},\left(\beta+a_{1}\right), \sigma, \rho ; \varepsilon, \varphi\right) f(\varepsilon, \varphi) d \varepsilon d \varphi}
$$

where we use the estimated values of the parameters $a_{0},\left(\beta+a_{1}\right), \sigma$ and $\rho$. The likelihood $l_{q}$ of observing $x_{k}$ museum visits by household $k$ can thus be written as: 


$$
l_{q}(k)=\iint_{\varepsilon} g\left(x_{k} \mid \eta, \gamma, \alpha, \lambda ; \varepsilon, \varphi\right) w(k \mid \varepsilon, \varphi) f(\varepsilon, \varphi) d \varepsilon d \varphi
$$

where $g\left(x_{k} \mid.\right)$ is the conditional negative binomial density function for at least one museum visit, which has now been written as a function of the parameters to be estimated and the random variables over which integration takes place. Estimation proceeds by simulated maximum likelihood.

\section{Estimation results}

\subsection{Trip distribution model}

The likelihood for an individual household formulated in (30) was used as the basis for the likelihood function of the sample. We started with estimating the standard logit model with deterministic coefficients and an equal distance decay parameter for all destinations and subsequently introduced the generalizations discussed in the previous section. Table 1 gives the loglikelihood of the models that have been estimated.

Table 1 Estimation results for the trip distribution model

\begin{tabular}{lrr}
\hline Model & Loglikelihood & \#coeff \\
\hline Basic model (standard logit) & -836067.59 & 108 \\
+ Random parameters & -799362.76 & 216 \\
+ Correlated attractiveness & -797963.55 & 222 \\
+ Different distance decay parameters & -743404.60 & 329 \\
+ Income dependent destination choice and distance decay & -743288.08 & 437 \\
& & \\
Number of museum visits (school holiday periods excluded) & 245,020 \\
Number of card holders in sample & 69,643 \\
\hline
\end{tabular}

We started with the standard logit model. Allowing for heterogeneity in the parameters led to a substantial increase in the likelihood. Allowing the attractiveness of museums within the same group to be correlated also increased the loglikelihood substantially. The model still used the same distance decay parameters for all museum visits, thereby excluding the possibility of local effects. Allowing for these effects, by adding the parameter $a_{i}$ again resulted in a substantial increase in the loglikelihood. Finally we also introduced the possibility of income effects. Here, the results were somewhat ambiguous: a t-test shows that many coefficients are not significant and the increase in the value of the loglikelihood is less dramatic. However, a likelihood ratio test indicates that addition of the income coefficients is worthwhile and we therefore choose the model incorporating these income effects as our preferred specification.

All models, except the first one, are estimated by means of maximum simulated likelihood. We used $114 \times 250$ independent draws ${ }^{9}$ from the standard normal distribution for each household in the sample. Complete estimation results are reported in the Appendix.

\footnotetext{
${ }^{9}$ There are 114 random coefficients, so we have 250 independent draws for each coefficient.
} 


\section{Distance decay effects}

We start our discussion with the distance decay parameters $\left(\beta_{0}+a_{1 i}\right)$, which reflect a 'pure' distance decay effect and a possible 'local interest' effect. Since the latter will cause a stronger distance decay effect, this suggests that the minimum absolute value of the estimated parameter can be considered to be the pure distance decay effect. Moreover, one would expect that museums with a clear national interest, such as the Rijksmuseum in Amsterdam would have this minimum value of the distance decay parameters. Actual estimation results did not completely confirm this expectation. Table 2 lists a number of these coefficients.

Table 2 Some estimated distance decay parameters

\begin{tabular}{llc}
\hline Museum & Location & Dist decay \\
\hline 10 highest distance decay effects & & \\
\hline Mill Museum & Koog a/d Zaan & -14.17 \\
Regional Museum & Krimpen a/d Ijssel & -7.20 \\
Hortus Botanicus & Leyden & -5.11 \\
Town Mill Museum & Leyden & -4.96 \\
University Museum & Utrecht & -4.79 \\
Railway Museum & Utrecht & -4.30 \\
Resistance Museum & Amsterdam & -4.26 \\
Zaans Museum & Zaandam & -4.22 \\
Museum Beeckestein & Velsen-Zuid & -4.19 \\
Groeneveld Castle & Baarn & -4.14 \\
& & \\
5 Museums with a national interest & & -2.48 \\
\hline Rijksmuseum & Amsterdam & -1.95 \\
Van Goghmuseum & Amsterdam & -2.73 \\
Town Museum & Amsterdam & -2.76 \\
Zuiderzee museum & Enkhuizen & -2.42 \\
Boijmans van Beuningen & Rotterdam & \\
& & -1.16 \\
10 lowest distance decay effects & & -1.28 \\
\hline Groningen Museum & Groningen & -1.44 \\
Dutch Bakery Museum & Hattem & -1.46 \\
Toys and Tin Museum & Deventer & -1.47 \\
Bonnefantenmuseum & Maastricht & -1.71 \\
Industrion & Kerkrade & -1.74 \\
Princessehof & Leeuwarden & -1.76 \\
Loo Palace & Apeldoorn & -1.77 \\
Frisian Museum & Leeuwarden & -1.84 \\
Historical Museum & Deventer & \\
Northern Shipping Museum & Groningen & \\
\hline
\end{tabular}

The first panel gives the 10 museums with the strongest distance decay effects. With the exception of the Railway Museum, these are all museums with a clear local interest. The second panel gives the parameters of 5 museums which clearly have a national interest. Three well known Amsterdam museums and one Rotterdam museum, all specializing in visual arts, and a museum in Enkhuizen specialized in cultural history and a popular destination for day trips. All these museums have a distance decay effect that is much smaller than the 10 highest, which confirms our expectation. However, the estimated effects for these five museums still show 
significant differences, both in a statistical and economic sense. For no obvious reason the Van Gogh museum has a much lower distance decay parameter than the other four in this group.

Moreover, these five museums do not have the lowest distance decay effects (in absolute value) of the total set.

The ten museums with the lowest distance decay effect are listed in the bottom panel of Table 2 . Most of them are museums that specialize in a topic of general interest such as the history of baking or shipping, or the history of a province. All of them are located outside the Randstad, many of them in areas that are often used as destination for a short vacation. ${ }^{10}$ This suggests that deleting the trips made during school holiday periods has not resulted in a complete elimination of the trips that are made from other location than the household residence.

The effect of income on the distance decay parameter is small and insignificant. There is significant heterogeneity in the distance decay effect, with a standard deviation approximately equal to 1 .

These results imply that we do not have clear results with respect to the 'pure' distance decay parameter. The frequency distribution of the estimated parameters is shown in Figure 1.

Figure 1. Frequency distribution of distance decay parameters

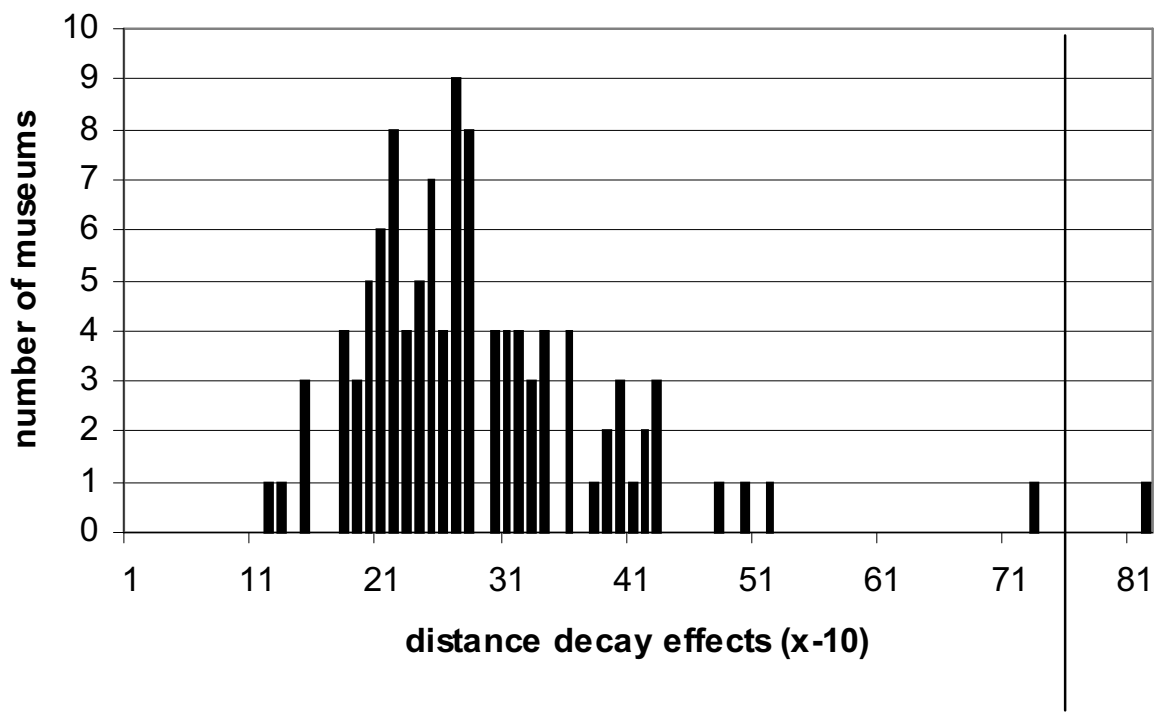

Its skewness is related to the local interest effect, and this disqualifies the mean as a useful indicator. Use of the mode is also problematic, since there is not a clear mode. There are 8 museums with a distance decay parameter in the interval $(-2.3,-2.2), 9$ in the interval $(-2.7,-2.6)$ and 8 in the interval $(-2.8,-2.7)$. The figures reported in Table 2 also make clear that there is variation among the distance decay effects of museum with an obvious national interest. The median of the frequency distribution, which is equal to -2.65 , is also difficult to interpret as the 'pure' distance decay effect. We have ultimately decided to use the distance decay parameter of the Rijksmuseum, being the national museum 'par excellence' as the best approximation of the pure distance decay effect. Coefficients that are smaller (in absolute value) are interpreted as the

\footnotetext{
${ }^{10}$ Kerkrade and Maastricht are in the southern part of Limburg, Hattem and Apeldoorn at the Veluwe; both regions are popular destinations for short holidays.
} 
product of the pure distance decay effect (which is equal to 2.48) and the fraction of travel time that can be attributed to the museum visit.

\section{Attractiveness}

We have computed the average attractiveness of the museums for consumers as the expected value of the lognormal distributed variable $A_{i k}$ of (31b). ${ }^{11}$ The parameter $a_{1 i}$, representing the local interest effect was set equal to the estimated values of $\left(\beta_{0}+a_{1 i}\right)$ minus the 'pure' distance decay effect, which was set equal to -2.48 whenever this was negative and to 0 in all other cases. This procedure is based on the discussion of the previous section. In order to moderate the effect of the 'local interest' effect, we computed the attractiveness of museums on the basis of a trip length of 44.9 minutes, the average travel time for a museum visit when undertaken from the residential location. In these computations income was set to its average value. Table 3 gives the average attractiveness of the top twenty museums.

Table 3 The 20 museums with highest attractiveness

\begin{tabular}{lllr}
\hline Name & Location & Group & Attractiveness \\
\hline Town Museum & Amsterdam & Visual arts & 6.90 \\
Rijksmuseum & Amsterdam & Visual arts/Cultural history & 5.89 \\
Naturalis & Leyden & Natural history & 2.18 \\
Cobra Museum & Amstelveen & Visual arts & 2.06 \\
Municipal Museum & The Hague & Cultural history & 1.91 \\
Singer Museum & Laren & Visual arts & 1.86 \\
Boijmans van Beuningen & Rotterdam & Visual arts & 1.59 \\
Hortus Botanicus & Leyden & Natural history & 1.56 \\
Van Gogh Museum & Amsterdam & Visual arts & 1.35 \\
Groningen Museum & Groningen & Visual arts/Cultural history & 1.27 \\
Tropical Museum & Amsterdam & Anthropology & 1.24 \\
Zuiderzee Museum & Enkhuizen & Cultural history & 1.19 \\
Railway Museum & Utrecht & Technology & 1.16 \\
Ecodrome & Zwolle & Natural history & 1.01 \\
Mauritshuis & The Hague & Visual arts & 0.90 \\
Frisia Museum & Hoorn & Visual arts & 0.90 \\
Bonnefanten & Maastricht & Visual arts & 0.85 \\
Dutch Architecture Museum & Rotterdam & Technology & 0.83 \\
Historical Museum & Amsterdam & Cultural history & 0.81 \\
Kranenburg & Bergen & Visual arts & 0.77 \\
\hline
\end{tabular}

Perhaps somewhat surprisingly, the first place is occupied by the Town Museum of Amsterdam, while the Rijksmuseum only takes the second place. The Rijksmuseum has a larger basic attractiveness parameter $a_{0}$, but the heterogeneity parameter for the Town Museum is much larger. Moreover, there is a relatively large and significant effect of income on the attractiveness of the Town Museum, and none on the attractiveness of the Rijksmuseum.

A large share $(50 \%)$ of the top twenty museums specialize in visual arts, i.e. paintings and sculptures, whereas only four of them belong to the much larger group of museums focusing on cultural history. The group of museums specializing in natural history is also well represented

\footnotetext{
${ }^{11}$ The computation uses $E\left(A_{i}\right)=\exp \left(a_{0 i}+a_{1 i} \pi^{a v}+a_{2 i} \ln \left(y^{a v}\right)+.5\left(\sigma_{\mathrm{i}}+\Sigma \rho_{l} d_{i, l}\right)^{2}\right)$ where the superscript $a v$ is used to denote sample averages. The determination of $a_{1 i}$ is discussed in what follows.
} 
with 3 of its members in the top 20; two of these museums are located in Leyden. Even though the Hortus Botanicus (the University Botanical Garden) in this town has a large local interest component (see Table 2), its attractiveness remains substantial for those who have to travel three quarters of an hour. The Railway Museum is another member of the top twenty group that has a substantial local interest component in its attractiveness. Together with the Architecture Museum it represents the group of technology museums in the top 20.

In interpreting the figures in Table 3, it must be kept in mind that they refer to the attractiveness for a very large, but specific group, namely holders of the Museum Card; people that estimate to go more often to museums, as the purchase is only worthwhile when planning to visit more than three museums per year. If we had estimated a model on trips of a different group, we would probably have found a different ranking. For instance, it seems likely that international tourists have a higher preference for the Rijksmuseum and the Van Gogh museum, and are less acquainted with, for instance, the Zuiderzee museum, which specializes in a particular Dutch theme.

Figure 2 shows the frequency distribution of the estimated expected attractiveness of the 108 museums. The most salient feature of the figure is the large numbers of museums with a very low attractiveness and the small number of museums with a very high attractiveness. The Town Museum of Amsterdam and the Rijksmuseum have an estimated attractiveness that is more than two times as high as that of any other museum. ${ }^{12}$ This phenomenon has been observed earlier and also in other contexts, see Frey (1998).

Figure 2 Frequency distribution of estimated attractiveness of museums

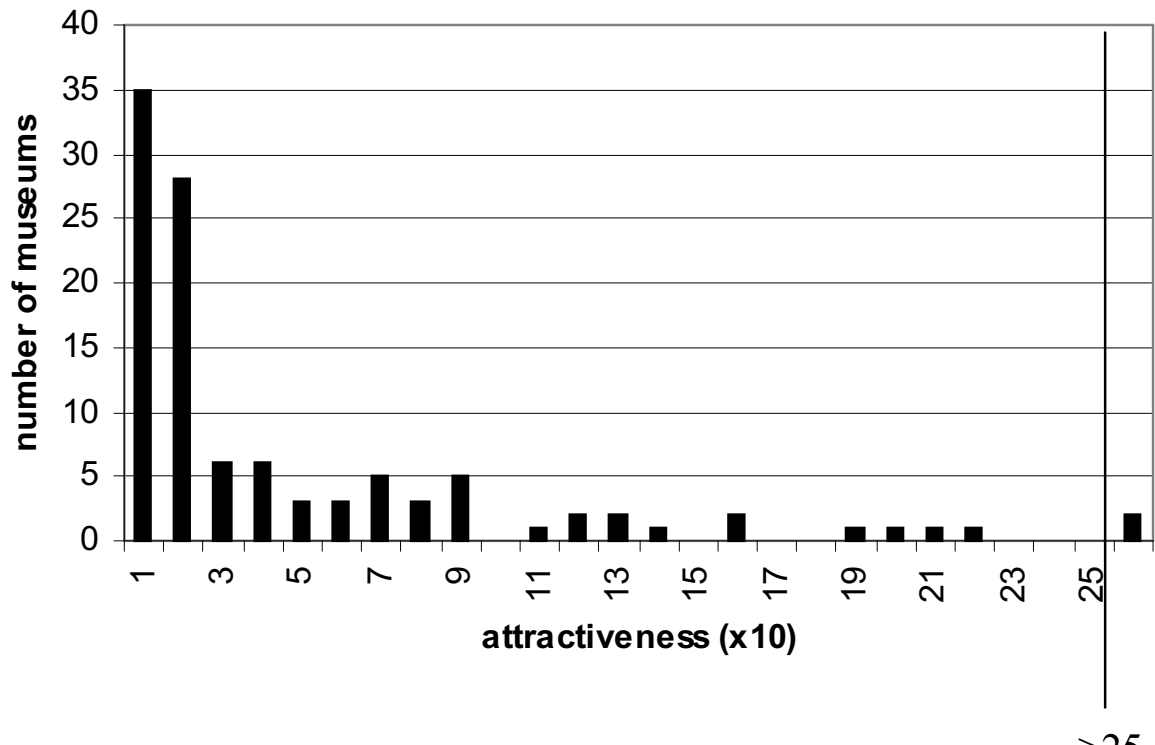

\footnotetext{
${ }^{12}$ This is not an artefact of our use of the lognormal distribution for heterogeneity among consumers. The phenomenon is also present in the basic logit model and appear also if we use only the parameters $a_{0}$.
} 
The effect of income on the attractiveness of most, but not all, museums is small and statistically insignificant. This result may partly be due to measurement error in this variable, which was only available as an average referring to an area defined by a particular zip code. The museums with significant positive or negative income effects on their attractiveness did not constitute a recognizable group.

Although the results reported in Table 3 and Figure 2 are dependent on our particular choice of the 'pure' distance decay effect, they are not very sensitive to changes in the value of this parameter. For instance, choice of the median value of $\left(\beta_{0}+a_{1 i}\right),-2.65$, as the pure distance decay effects does not change the set of top 20 museums, although their order is now different. Also choice of a smaller value does not result in substantial difference in Table 3.

Before concluding this subsection we should note that attractiveness of a museum is not identical with its value in a welfare economic sense. The welfare economic aspects of the model will be discussed in subsection 4.3.

\subsection{Trip generation model}

Since income effects were found to be significant in the trip distribution model, we used equation (34) for the expected number of trips. The value of the partial derivative $\partial w^{\prime} / \partial y$ was determined on the basis of the estimation results reported in the previous subsection. Its value turned out to be close to zero in all cases. The reason is that the distance decay parameters is not dependent on income, whereas the income effects on the attractiveness of museums are sometimes positive and sometimes negative, with the net effect close to zero. As a consequence, the difference between (16) and (34) is very small and ignoring the effect of income on the composite price of museum has only small effects the results of the count data model.

Estimation results for the negative binomial model are presented in Table $4 .{ }^{13}$ They have been obtained while taking into account the dependence of the composite price of museum trips on income. The composite price of museum visits has a significant negative effect on the number of trips. The price elasticity is equal to $\eta \pi^{*}$, which is on average equal to -1.28 . There is also a significant positive effect of income. The income elasticity of the demand for museum trips is equal to $\alpha$, suggesting that such trips are a necessity. ${ }^{14}$ There is a significant amount of overdispersion present in our data, implying that the simple Poisson model would be inappropriate. ${ }^{15}$ The overdispersion is reflected in the presence of a few households with a very large number of museum visits in our data.

Table 4 Estimation results for the count data model

\begin{tabular}{llll}
\hline Coefficient & Variable & Estimate & Standard error \\
\hline$\gamma$ & Constant & -1.76 & 0.27 \\
$\eta$ & Price & -0.596 & 0.016 \\
$\alpha$ & Ln(Income) & 0.189 & 0.029 \\
$\lambda$ & Overdispersion & 3.582 & 0.102 \\
Loglikelihood & & $-136,630$ & \\
\hline
\end{tabular}

\footnotetext{
${ }^{13}$ The standard errors reported in this table have been computed treating the estimated coefficients of the trip distribution model as constants.

${ }^{14}$ The measurement error implied by our use of the average income (expressed in euros per year) per zip code area may have resulted in a downward bias for this elasticity.

${ }^{15}$ Because our data are truncated, estimating a Poisson model would probably not result in unbiased estimates.
} 


\subsection{Welfare economic implications}

In order to assess the implications of the estimated model we use the compensating variation formula (26). In order to apply it, we have to take into account that $w^{\prime}$ is, according to our empirical model, a random variable. Moreover, the observed behavior with respect to destination choice can be used to improve the estimated value of the compensating variation for each consumer. Our computations will therefore make use of the posterior distribution of the random variables $\varepsilon$ and $\varphi$. The procedure is analogous to that used in estimating the count data model. Our computation uses the formula:

$$
E V_{i}(k)=\iint_{\varepsilon} V_{i}(\varepsilon, \varphi) w(k \mid \varepsilon, \varphi) f(\varepsilon, \varphi) d \varepsilon d \varphi
$$

where $V_{i}($.$) is the expression given in (26), which is now written as a function of the standard$ normal random variables $\varepsilon$ and $\varphi$. The weights $w($.$) were defined in (36). In order to assess the$ total value of a museum for the group of households under consideration, $E V_{i}(k)$ has to be summed over all households in our sample.

Before carrying out these computations, we have to recall that we have used travel time as the 'price' of a museum trip, whereas we now want to compute a monetary measure of welfare. The (monetary) price of a trip is the value of the travel time involved, which equals vot $\pi_{i}$, where vot is the value of time. For the Netherlands the figure of 7.5 euros is often used for this variable. The estimated distance decay parameters are based on travel time and can be interpreted as the product of the vot and the distance decay parameter that refers to the monetary value of travel time. The composite price $w^{\prime}$ will also refer to travel time when computed on the basis of the estimated coefficients, and should therefore be multiplied by the vot in order to find the associated monetary value. In estimating the count data model for the number of trips we have used the composite price based on travel time. This means that the estimated value of the parameter $\eta$ must therefore also be interpreted as the product of the vot and the price parameter that refers to a monetary price.

Table 5. Values of selected museums

\begin{tabular}{lrrrr}
\hline & $\begin{array}{r}\text { Compensating } \\
\text { variation }\end{array}$ & $\begin{array}{r}\Delta \text { logsum * } \\
\text { predicted \# } \\
\text { visits }\end{array}$ & $\begin{array}{r}\Delta \text { Predicted } \\
\text { \# visits }\end{array}$ & $\begin{array}{r}\mathbf{4} \\
\text { observed \# visits }\end{array}$ \\
\hline Town Museum & -0.388 & -0.408 & -0.03 & -0.907 \\
Rijksmuseum & -0.509 & -0.525 & -0.04 & -1.223 \\
Naturalis & -0.116 & -0.119 & -0.01 & -0.232 \\
Van Gogh museum & -0.276 & -0.278 & -0.02 & -0.644 \\
Groningen Museum & -0.424 & -0.457 & -0.03 & -0.816 \\
\hline
\end{tabular}

Results of the computations for five selected museum are given in Table 5. The value of a museum is determined by removing it from the set of museums. A new (lower) value of $w^{\prime}$ for the remaining 107 museum is then computed and the compensating variation of the change in $w^{\prime}$ is determined. This procedure assumes that the museum disappears and is equivalent to letting the 
price $\pi_{i}$ become infinitely high ${ }^{16}$ or the attractiveness $A_{i}$ go to zero. In our computations we use all the estimated parameters of the trip distribution model. This means that we do not only take into account the local interest effect, but also the 'holiday effect' that is probably present in the lower absolute value of the estimated distance decay parameters for some museums. The reason for proceeding in this way is that here we are concerned with the effect of the presence of the museum on welfare. The local interest effect implies that households at a greater distance value a museum less than those living close by, whereas the holiday effect results in a larger contribution to welfare than would be estimated on the basis of travel cost between the residential location and the museum.

The figures in this table are averages over all households in the sample. Column 1 reports the compensating variation of disappearance of the museum as given in (38). The Table indicates, for instance, that disappearance of the Town Museum of Amsterdam would result in a loss of consumer welfare that can on average be compensated by an increase in income of almost .40 euros. The compensating variations computed for the other museums are of the same order of magnitude. These values are probably smaller than one would expect and certainly much smaller than the value of the average travel time that has to be spent when these museums are visited. The reason is that there are many museums and that they appear to be good substitutes. The disappearance of any single museum, including those with the highest attractiveness, would therefore not imply a substantial loss in consumer welfare.

The Table shows that the ranking of the museum on the basis of the compensating variation associated with their disappearance differs substantially from that based on attractiveness. For instance, the Rijksmuseum is valued higher than the Amsterdam Town Museum. This reversal is related to the local interest effect of the Town Museum, which gives the Rijksmuseum a higher value for visitors outside the Randstad. Note also that value attached to the Van Gogh museum exceeds that of the Naturalis Museum, which was ranked $3^{\text {rd }}$ on the basis of its attractiveness. The reason is the relatively low distance decay effect estimated for this museum. Even more surprising is the high score of the Groningen Museum, which is explained partly by its low distance decay parameter, but also by the lack of good substitutes in the northern part of the country.

Column 2 of the Table shows the product of the predicted number of visits for the 108 museums and the change in the logsum term. This measure ignores the effect of the disappearance of the museum on the number of trips, but is otherwise comparable to the compensating variation. Since the change in the number of trips induced by the disappearance of a single museum is small, as shown in column 3 , the difference between this approximate welfare indicator and the compensating variation is small. However, column 4 shows that this does not imply that the logsum welfare measure, which multiplies the change in the logsum by the number of trips is approximately equal to the compensating variation. The traditional measure is approximately two times as large as the compensating variation. An important reason for this relatively large discrepancy is that the traditional measure uses the observed number of trips (which is at least equal to 1) whereas the compensating variation is based on the predicted number of trips, which may be smaller. Since we found a substantial amount of overdispersion in our trip generation model, there is a nonnegligable probability that a household in our sample will not visit any museum in a given year, even if its expected number of visits is large. The result is that the

\footnotetext{
${ }^{16}$ The procedure adopted here avoids possible problems associated with the fact that the random distance decay parameter may be positive, even though the probability that this happens is small.
} 
expected number of trips of a sample of households that have realized at least one trip is smaller than the average observed number of trips in the sample.

\section{Conclusion}

In this paper we have developed and estimated a model that explains the number of museum visits and their destination on the basis of a consistent utility maximizing analytical framework. The separable indirect utility function allows for a procedure in which trip generation and destination choice can be regarded as two stages of the planning process. Estimation of the destination choice model takes into account the unobserved heterogeneity among the households in our sample and the existence of local interest effects. Both are found to be of substantial importance. The two-stage procedure used here can deal with an income effect in the second stage, which was found to be significant.

The welfare economic analysis shows that the welfare effect of disappearance of a museum depends on the availability of good substitutes at or close to the same destination. For this reason, the disappearance of the Rijksmuseum, which is one of the many museums in Amsterdam, is relatively small in comparison to that of the Groningen Museum, which is virtually the only large museum in the northern part of the Netherlands. Because of this 'spatial competition' effect there is a substantial difference between the ranking of the museum based on attractivity and that based on compensating variation.

The model developed in this paper implies that the change in the logsum variable of the destination choice, multiplied by the number of visits does not give the total welfare effect. An intuitive reason is that an analysis that only considers destination choices cannot account for effects on the number of trips. Even though our computations show that the effect of disappearance of a museum on the number of trips is modest, especially if good substitutes are available, it is important to be able to investigate this effect rather than being forced to ignore it. The difference between the effects computed on the basis of the logsum variable and those based on the complete model are determined in large part by the fact that we estimate a large random component in the determination of the annual number of trips. Since the computation of the compensating variation is based on the expected number of trips, which will be lower than the average observed number of trips in a sample of households that have undertaken at least one trip, the product of the change in the logsum and the number of trips typically suggest a larger welfare losses than the compensating variation.

Even though the compensating variation of museum are perhaps smaller than was expected by the reader, it should be observed that these values are certainly not negligible. There are approximately 6 million households in the Netherlands and even if their average valuation of museums is smaller than that of the households in our sample, the total value is probably considerable. Note also that our computations have implicitly assumed that trips are undertaken by single persons whereas the average number of visitors per households is probably larger than 1. Also, one must remember that foreign tourists with an interest in especially the most highly ranked museums, and their valuation of the museums have not been taken into account. Recent analyses have brought the importance of consumer amenities for the attractiveness of cities to the fore (see Brueckner, Thisse and Zenou, 1999; Glaeser, Kolko and Saiz, 2000). If these analyses are correct, amenities - like museums - may well be an important reason for choosing a residential location in an urban area. Households that attach a high value to museums may therefore choose a location with a good museum accessibility, probably implying that our estimates of the value of museum are downward biased. This phenomenon may partly be reflected in an effect of the presence of museums on the value of nearby housing. 
Finally, it may be noted that our analysis is concerned only with the value of museums to visitors, often referred to as the 'use value'. People may also value museums for other reasons, such as the option to visit it later ('option value'), the option to preserve it for future generations ('bequest value'), or simply the fact that it is there ('existence value') (Frey 2003). Contingent valuation is often regarded as an appropriate tool for investigating such non-use values. ${ }^{17}$. For use values, however, travel cost methods seem more valid, as they measure revealed preferences, rather than a hypothetical willingness. As such, the few travel cost applications in this area compares bleakly with the large number of stated preference applications (Navrud and Ready 2002). We hope that the present study may contribute to remedy this state of affairs.

\section{References}

Blackorby, C., D. Primont and R. Russell (1978) Duality, Separability and Functional Structure, New York, American Elsevier.

Boter, Jaap, Jan Rouwendal and Michel Wedel (2005), "Employing Travel Time to Compare the Value of Competing Cultural Organizations," Journal of Cultural Economics, forthcoming.

Brueckner, J.K., J.F. Thisse and Y. Zenou (1999) Why is Central Paris Rich and Downtown Detroit Poor? An Amenity-based Theory. European Economic Review, 43, 91-107.

Cameron, A.C. and K. Trivedi (1998) Regression Analysis of Count Data, Cambridge University Press, Cambridge.

Clawson, M. (1959) A Method for Measuring the Demand for, and the Value of Outdoor Recreation, Resources for the Future, Washington (DC).

Clawson. M. and J.L. Knetsch (1966) Economics of Outdoor Recreation, Johns Hopkins, Washington (DC).

Eurobarometer (2002), Europeans' Participation in Cultural Activities . Eurostat, Brussels/Strasbourg. (Available at http://europa.eu.int/comm/public_opinion/archives/eb/ ebs_158_en.pdf)

Forrest, David, Grime, Keith, and Woods, Robert (2000) "Is It Worth Subsidizing Regional Repertory Theatre?", Oxford Economic Papers 52: 381-397.

Frey, B.S. (1998) Superstar Museums. Journal of Cultural Economics, 22, 113-125.

Frey, B.S. and S. Meier (2003) The Economics of Museums, working paper 149, Institute for Empirical Research in Economics, University of Zurich. (Forthcoming in:Ginsburgh and Throsby (eds) Handbook of Economics of At and Culture, Elsevier.)

Glaeser, E.L., J. Kolko and A. Saiz (2000) Consumer City. Journal of Economic Geography

Gorman (1959) Separable Utility and Aggregation. Econometrica, 27, 469-481.

Hausman, J.A., G.K. Leonard and D. McFadden (1995) A Utility-Consistent, Combined Discrete Choice and Count Data Model Assessing Recreational Use Losses Due to Natural Resource Damage, Journal of Public Economics, 56, 1-30.

Johnson, P. and B. Thomas (1998) The Economics of Museums: A Research Perspective, Journal of Cultural Economics, 22, 75-85.

Martin, Fernand (1994) Determining the Size of Museum Subsidies. Journal of Cultural Economics 18: 255-270.

McFadden, D. (1974) Conditional Logit Analysis for Qualitative Choice Behavior. In: P. Zarembka (ed.) Frontiers in Econometrics, Academic Press, New York, 105-142.

\footnotetext{
${ }^{17}$ Tohmo, 2004, is a recent example referring to a local museum
} 
McFadden, D. (1981) Econometric Models of Probabilistic Choice. In: D. McFadden and C.F. Manski (eds) Structural Analysis of Discrete Data, MIT Press, Cambridge, 198-271.

Navrud, Ståle and Ready, Richard C. (2002) Valuing Cultural Heritage; Applying Environmental Techniques to Historic Buildings, Monuments and Artifacts . Edward Elgar, Cheltenham.

NEA (1998) 1997 Survey of Public Participation in the Arts (Research Division Report \# 39). National Endowment for the Arts, Washington, DC. (Available at http://arts.endow.gov/pub/ Survey/Survey.pdf)

Poor, P. Joan and Smith, Jamie M (2004) Travel Cost Analysis of a Cultural Heritage Site: The Case of Historic St. Mary's City of Maryland. Journal of Cultural Economics 28: 217229.

Strotz, R.H. (1957) The Empirical Implications of a Utility Tree. Econometrica, 25, 269-280.

Tohmo, T. (2004) Economic Value of a Local Museum; Factors of Willingness-to-pay. Journal of Socio-Economics, 33: 229-240.

Train, K. (200.) Discrete Choice Methods with Simulation, Cambridge University Press, Cambridge. 


\section{Appendix A. The 108 museums}

\begin{tabular}{|c|c|c|c|}
\hline $\mathbf{N r}$ & Museum & Location & Collection Category Codes \\
\hline 1 & Groninger Museum & Groningen & Visual arts/cultural history \\
\hline 2 & Noordelijk Scheepvaartmuseum & Groningen & Maritime \\
\hline 3 & Museum Willem van Haren & Heerenveen & Cultural history \\
\hline 4 & Fries Museum & Leeuwarden & Cultural history \\
\hline 5 & Fries Natuurmuseum & Leeuwarden & Natural history \\
\hline 6 & Princessehof Leeuwarden & Leeuwarden & Cultural history \\
\hline 7 & Natuurcentrum Ameland & Nes Ameland & Natural history \\
\hline 8 & Fries Scheepvaart Museum & Sneek & Maritime \\
\hline 9 & Natuurmuseum Groningen & Groningen & Natural history \\
\hline 10 & Museum Kempenland & Eindhoven & Cultural history \\
\hline 11 & Stedelijk Museum Helmond & Helmond & Visual arts \\
\hline 12 & Industrion & Kerkrade & Technology \\
\hline 13 & Bonnefantenmuseum & Maastricht & Visual arts \\
\hline 14 & Nederlands Textielmuseum & Tilburg & Technology \\
\hline 15 & Natuurmuseum Brabant & Tilburg & Natural history \\
\hline 16 & Limburgs Museum & Venlo & Cultural history \\
\hline 17 & Stadspaleis Het Markiezenhof & Bergen op Zoom & Cultural history \\
\hline 18 & Gorcums Museum & Gorinchem & Cultural history \\
\hline 19 & Museum Catharina Gasthuis & Gouda & Cultural history \\
\hline 20 & Haags Gemeentemuseum & The Hague & Cultural history \\
\hline 21 & Museum voor Communicatie & The Hague & Technology \\
\hline 22 & Museon & The Hague & Other \\
\hline 23 & Nationaal Glasmuseum & Leerdam & Cultural history \\
\hline 24 & Hortus Botanicus Leiden & Leiden & Natural history \\
\hline 25 & Stedelijk Molenmuseum De Valk & Leiden & Technology \\
\hline 26 & Stedelijk Museum De Lakenhal & Leiden & Visual arts \\
\hline 27 & Zeeuws Biologisch Museum & Oostkapelle & Natural history \\
\hline 28 & Museum Rijswijk (Het Tollenshuis) & Rijswijk zh & Cultural history \\
\hline 29 & Mariniersmuseum & Rotterdam & Cultural history \\
\hline 30 & Museum Boijmans Van Beuningen & Rotterdam & Visual arts \\
\hline 31 & het Schielandshuis & Rotterdam & Cultural history \\
\hline 32 & Zeemuseum & Scheveningen & Natural history \\
\hline 33 & Goud-, Zilver- en Klokkenmuseum & Schoonhoven & Cultural history \\
\hline 34 & Rijksmuseum voor Volkenkunde & Leiden & Anthropology \\
\hline 35 & De Dubbelde Palmboom & Rotterdam & Cultural history \\
\hline 36 & Haags Historisch Museum & The Hague & Cultural history \\
\hline 37 & Nationaal Schoolmuseum & Rotterdam & Cultural history \\
\hline 38 & Letterkundig/Kinderboekenmuseum & The Hague & Cultural history \\
\hline 39 & Nederlands Architectuur Instituut & Rotterdam & Technology \\
\hline 40 & Museum Flehite & Amersfoort & Cultural history \\
\hline 41 & Kasteel Groeneveld & Baarn & Natural history \\
\hline 42 & Afrika Museum & Berg en Dal & Anthropology \\
\hline 43 & Natura Docet Natuurmuseum & Denekamp & Natural history \\
\hline 44 & Historisch Museum DeWaag & Deventer & Cultural history \\
\hline 45 & Nationaal Bevrijdingsmuseum & Groesbeek & Cultural history \\
\hline 46 & Nederlands Bakkerijmuseum & Hattem & Cultural history \\
\hline 47 & Singer Museum & Laren nh & Visual arts \\
\hline 48 & Nieuw Land Poldermuseum & Lelystad & Cultural history \\
\hline 49 & Het Nederlands Vestingmuseum & Naarden & Cultural history \\
\hline 50 & Museum Het Valkhof & Nijmegen & Visual arts \\
\hline 51 & Nat. Mus. Speelklok tot Pierement & Utrecht & Technology \\
\hline 52 & Nederlands Spoorwegmuseum & Utrecht & Technology \\
\hline 53 & Stedelijk Museum Zutphen & Zutphen & Cultural history \\
\hline 54 & Stedelijk Museum Zwolle & Zwolle & Cultural history \\
\hline 55 & Speelgoed- en Blikmuseum & Deventer & Cultural history \\
\hline 56 & Museum Schokland & Ens & Cultural history \\
\hline 57 & Kasteel Huis Doorn & Doorn & Cultural history \\
\hline 58 & Stedelijk Museum Alkmaar & Alkmaar & Cultural history \\
\hline
\end{tabular}




\begin{tabular}{|c|c|c|c|}
\hline 59 & Amsterdams Historisch Museum & Amsterdam & Cultural history \\
\hline 60 & Bijbels Museum & Amsterdam & Cultural history \\
\hline 61 & Museum Het Rembrandthuis & Amsterdam & Visual arts \\
\hline 62 & Joods Historisch Museum & Amsterdam & Cultural history \\
\hline 63 & Museum Amstelkring & Amsterdam & Cultural history \\
\hline 64 & Museum Willet-Holthuijsen & Amsterdam & Cultural history \\
\hline 65 & Stedelijk Museum Amsterdam & Amsterdam & Visual arts \\
\hline 66 & Theater Instituut Nederland & Amsterdam & Cultural history \\
\hline 67 & Tropenmuseum & Amsterdam & Anthropology \\
\hline 68 & Verzetsmuseum Amsterdam & Amsterdam & Cultural history \\
\hline 69 & Frans Halsmuseum & Haarlem & Visual arts \\
\hline 70 & Marinemuseum & Den Helder & Maritime \\
\hline 71 & Molenmuseum & Koog a/d Zaan & Technology \\
\hline 72 & Museum Beeckestijn & Velsen-zuid & Cultural history \\
\hline 73 & Museum Nederlandse Uurwerk & Zaandam & Technology \\
\hline 74 & Verweyhal/De Hallen & Haarlem & Visual arts \\
\hline 75 & Rijksmuseum Amsterdam & Amsterdam & Visual arts \\
\hline 76 & Nederlands Scheepvaartmuseum & Amsterdam & Maritime \\
\hline 77 & Van Gogh Museum & Amsterdam & Visual arts \\
\hline 78 & Paleis Het Loo Nationaal Museum & Apeldoorn & Cultural history \\
\hline 79 & Museum Slot Loevestein & Poederoijen & Cultural history \\
\hline 80 & Rijksmuseum Twenthe & Enschede & Visual arts \\
\hline 81 & Mauritshuis & The Hague & Visual arts \\
\hline 82 & Museum Gevangenpoort & The Hague & Cultural history \\
\hline 83 & Museum Mesdag & The Hague & Visual arts \\
\hline 84 & Teylers Museum & Haarlem & Technology \\
\hline 85 & Muiderslot & Muiden & Cultural history \\
\hline 86 & Museum Catharijneconvent & Utrecht & Cultural history \\
\hline 87 & Museum Boerhaave & Leiden & Technology \\
\hline 88 & Zuiderzeemuseum & Enkhuizen & Cultural history \\
\hline 89 & Galerij Willem V & The Hague & Visual arts \\
\hline 90 & Historisch Museum Apeldoorn & Apeldoorn & Cultural history \\
\hline 91 & Museum voor Moderne Kunst & Arnhem & Visual arts \\
\hline 92 & Techniek Museum Delft & Delft & Technology \\
\hline 93 & Streekmuseum Crimpenerhof & Krimpen a/d IJssel & Cultural history \\
\hline 94 & Universiteitsmuseum & Utrecht & Cultural history \\
\hline 95 & Hannema-De Stuers Fundatie & Heino/Wijhe & Visual arts \\
\hline 96 & Naturalis & Leiden & Natural history \\
\hline 97 & Rien Poortvliet Museum & Middelharnis & Visual arts \\
\hline 98 & Museum Kranenburgh & Bergen & Visual arts \\
\hline 99 & Allard Pierson Museum & Amsterdam & General history \\
\hline 100 & Museum van het Boek & The Hague & Cultural history \\
\hline 101 & Museum van de Twintigste Eeuw & Hoorn & Cultural history \\
\hline 102 & Natuurmuseum Rotterdam & Rotterdam & Natural history \\
\hline 103 & Cobra Museum Amstelveen & Amstelveen & Visual arts \\
\hline 104 & Frisia Museum, Magisch Realisme & Hoorn & Visual arts \\
\hline 105 & Ecodrome & Zwolle & Natural history \\
\hline 106 & Armando Museum & Amersfoort & Visual arts \\
\hline 107 & Zaans Museum & Zaandam & Cultural history \\
\hline 108 & Aboriginal Art Museum & Utrecht & Visual arts \\
\hline
\end{tabular}




\section{Appendix B. Estimation results for the preferred destination choice model}

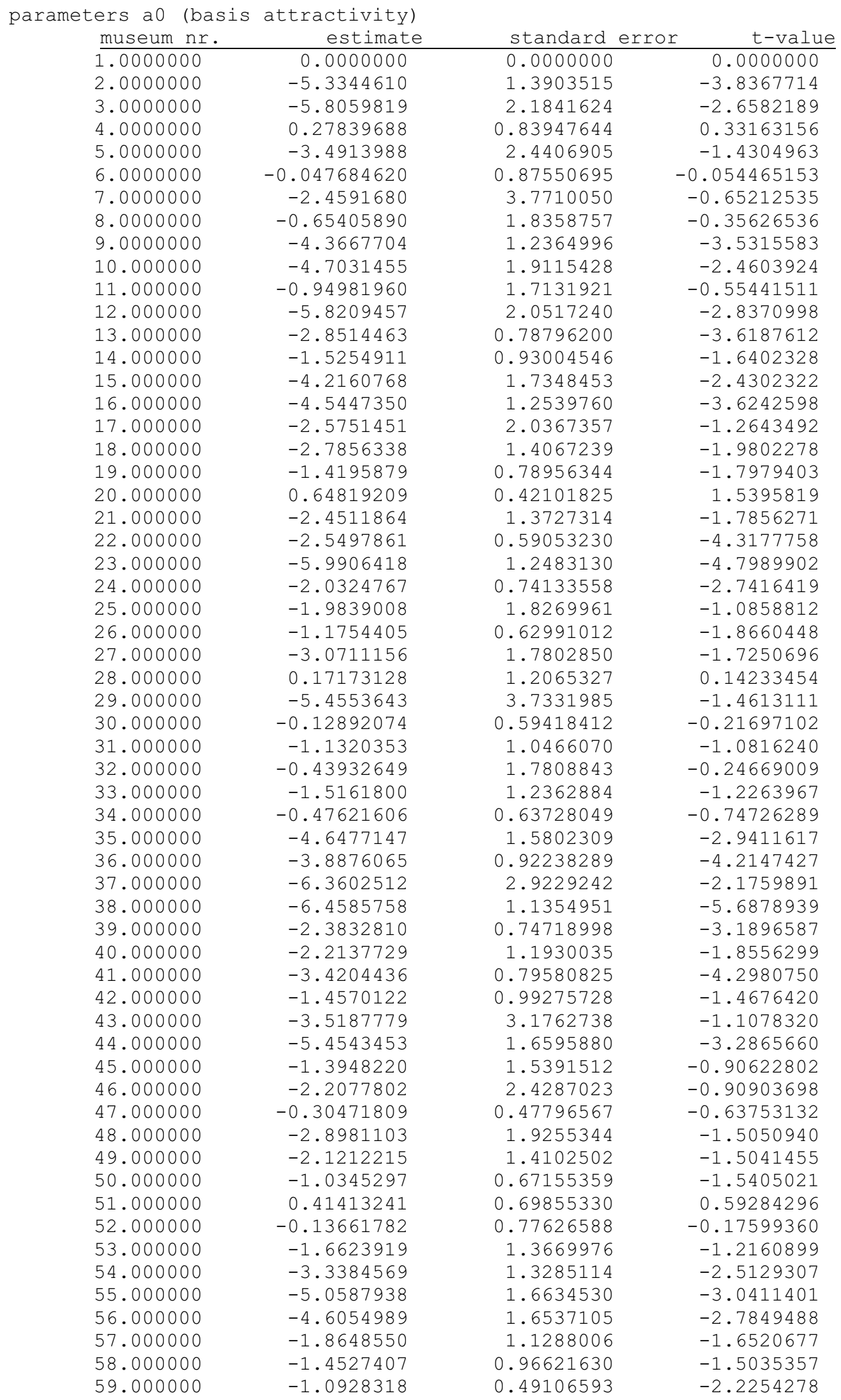




\begin{tabular}{|c|c|c|c|}
\hline 60.000000 & -2.1768939 & 0.71054639 & -3.0636900 \\
\hline 61.000000 & -2.0380223 & 0.58203762 & -3.5015303 \\
\hline 62.000000 & -0.37776751 & 0.50576335 & -0.74692544 \\
\hline 63.000000 & -1.4816939 & 0.94931339 & -1.5608059 \\
\hline 64.000000 & -4.5508614 & 0.85037401 & -5.3515999 \\
\hline 65.000000 & -1.5671175 & 0.45301857 & -3.4592787 \\
\hline 66.000000 & -3.3514334 & 1.1059768 & -3.0302926 \\
\hline 67.000000 & -1.3240544 & 0.63947796 & -2.0705239 \\
\hline 68.000000 & -4.2417104 & 1.1837922 & -3.5831546 \\
\hline 69.000000 & -0.72242860 & 0.56288329 & -1.2834430 \\
\hline 70.000000 & -3.4578910 & 1.4543163 & -2.3776747 \\
\hline 71.000000 & -8.3208853 & 2.0207068 & -4.1178094 \\
\hline 72.000000 & -1.1138302 & 1.9307719 & -0.57688338 \\
\hline 73.000000 & -5.8873147 & 2.1093154 & -2.7911022 \\
\hline 74.000000 & 1.0156501 & 0.76369644 & 1.3299134 \\
\hline 75.000000 & 0.80159599 & 0.39394062 & 2.0348143 \\
\hline 76.000000 & -1.6377144 & 0.54476875 & -3.0062561 \\
\hline 77.000000 & -0.14119461 & 0.42346251 & -0.33342884 \\
\hline 78.000000 & -1.1109603 & 0.58439757 & -1.9010350 \\
\hline 79.000000 & -4.5612719 & 1.5655361 & -2.9135527 \\
\hline 80.000000 & 0.28747239 & 1.2866478 & 0.22342741 \\
\hline 81.000000 & -0.36030952 & 0.48140161 & -0.74845931 \\
\hline 82.000000 & -2.2621874 & 1.4600032 & -1.5494400 \\
\hline 83.000000 & 0.60759194 & 0.86678346 & 0.70097316 \\
\hline 84.000000 & -0.90314331 & 0.65168949 & -1.3858491 \\
\hline 85.000000 & -3.2921800 & 0.99672542 & -3.3029960 \\
\hline 86.000000 & -1.3337412 & 0.54803909 & -2.4336606 \\
\hline 87.000000 & -0.93843492 & 1.0577645 & -0.88718704 \\
\hline 88.000000 & 0.083637478 & 0.66600547 & 0.12558077 \\
\hline 89.000000 & -3.5745797 & 1.2472158 & -2.8660474 \\
\hline 90.000000 & -6.5508326 & 2.2203531 & -2.9503563 \\
\hline 91.000000 & -1.0222852 & 0.63587798 & -1.6076752 \\
\hline 92.000000 & 0.67868362 & 1.8784050 & 0.36130847 \\
\hline 93.000000 & -6.2542715 & 4.8761073 & -1.2826361 \\
\hline 94.000000 & -1.8815494 & 1.0201425 & -1.8443986 \\
\hline 95.000000 & -2.1043055 & 1.4152075 & -1.4869236 \\
\hline 96.000000 & -1.3996557 & 0.57190098 & -2.4473742 \\
\hline 97.000000 & -5.2536621 & 2.5146106 & -2.0892547 \\
\hline 98.000000 & -0.70481391 & 0.89292478 & -0.78933179 \\
\hline 99.000000 & -3.6660909 & 0.81683340 & -4.4881746 \\
\hline 100.00000 & -2.1575676 & 1.1546532 & -1.8685850 \\
\hline 101.00000 & -3.6077269 & 1.1594504 & -3.1115838 \\
\hline 102.00000 & -0.12481353 & 1.4358353 & -0.086927468 \\
\hline 103.00000 & -0.12644603 & 0.48050470 & -0.26315253 \\
\hline 104.00000 & -0.021847837 & 0.77598156 & -0.028155098 \\
\hline 105.00000 & -2.7161430 & 1.1827279 & -2.2965072 \\
\hline 106.00000 & -2.2691335 & 1.4338840 & -1.5825084 \\
\hline 107.00000 & -5.7679933 & 1.3242943 & -4.3555221 \\
\hline 108.00000 & -2.4264377 & 0.90695148 & -2.6753777 \\
\hline
\end{tabular}

parameters a2 (log income)

\begin{tabular}{lrcr} 
museum nr. & estimate & standard error & t-value \\
\hline 1.0000000 & 0.0000000 & 0.0000000 & 0.0000000 \\
2.0000000 & 0.49273568 & 0.28839843 & 1.7085241 \\
3.0000000 & 0.76092808 & 0.45361015 & 1.6774935 \\
4.0000000 & -0.37426958 & 0.17444379 & -2.1455025 \\
5.0000000 & 0.091447061 & 0.50763221 & 0.18014432 \\
6.0000000 & -0.39690305 & 0.18114020 & -2.1911373 \\
7.0000000 & -0.15331640 & 0.73144129 & -0.20960863 \\
8.0000000 & -0.62782838 & 0.39026852 & -1.6087088 \\
9.0000000 & 0.37393320 & 0.25721514 & 1.4537760 \\
10.000000 & 0.50742612 & 0.39929040 & 1.2708198 \\
11.000000 & -0.33140106 & 0.35954039 & -0.92173527
\end{tabular}




\begin{tabular}{|c|c|c|c|}
\hline 12.000000 & 0.35719978 & 0.43573872 & 0.81975681 \\
\hline 13.000000 & 0.17305332 & 0.16395946 & 1.0554641 \\
\hline 14.000000 & -0.070402510 & 0.19351623 & -0.36380675 \\
\hline 15.000000 & 0.33449603 & 0.36354996 & 0.92008270 \\
\hline 16.000000 & 0.51691651 & 0.26097105 & 1.9807427 \\
\hline 17.000000 & -0.038288923 & 0.42210944 & -0.090708522 \\
\hline 18.000000 & 0.094004084 & 0.28999702 & 0.32415535 \\
\hline 19.000000 & 0.036943374 & 0.16433563 & 0.22480442 \\
\hline 20.000000 & -0.0036824861 & 0.087571589 & -0.042051151 \\
\hline 21.000000 & -0.081113674 & 0.29217045 & -0.27762450 \\
\hline 22.000000 & 0.41495281 & 0.12284177 & 3.3779456 \\
\hline 23.000000 & 0.70814403 & 0.26153737 & 2.7076208 \\
\hline 24.000000 & 0.13935449 & 0.15375051 & 0.90636763 \\
\hline 25.000000 & -0.11251230 & 0.38012610 & -0.29598677 \\
\hline 26.000000 & 0.075566852 & 0.13135418 & 0.57529081 \\
\hline 27.000000 & -0.13819123 & 0.37379380 & -0.36969911 \\
\hline 28.000000 & -0.66271942 & 0.24972823 & -2.6537625 \\
\hline 29.000000 & 0.34388626 & 0.78106527 & 0.44027851 \\
\hline 30.000000 & -0.16169108 & 0.12378342 & -1.3062418 \\
\hline 31.000000 & -0.016903811 & 0.21818688 & -0.077474002 \\
\hline 32.000000 & -0.59361360 & 0.36726892 & -1.6162914 \\
\hline 33.000000 & -0.10411488 & 0.25888758 & -0.40216249 \\
\hline 34.000000 & -0.058761070 & 0.13287215 & -0.44223766 \\
\hline 35.000000 & 0.44222849 & 0.32868434 & 1.3454504 \\
\hline 36.000000 & 0.45284893 & 0.19216839 & 2.3565214 \\
\hline 37.000000 & 0.56293105 & 0.58832094 & 0.95684347 \\
\hline 38.000000 & 0.67864682 & 0.23827858 & 2.8481234 \\
\hline 39.000000 & 0.040648273 & 0.15668084 & 0.25943359 \\
\hline 40.000000 & 0.13218802 & 0.24824098 & 0.53249880 \\
\hline 41.000000 & 0.46393281 & 0.16482639 & 2.8146756 \\
\hline 42.000000 & -0.23866283 & 0.20690274 & -1.1535025 \\
\hline 43.000000 & -0.043341764 & 0.66596606 & -0.065081040 \\
\hline 44.000000 & 0.37815192 & 0.34533051 & 1.0950435 \\
\hline 45.000000 & -0.37702857 & 0.32087184 & -1.1750130 \\
\hline 46.000000 & -0.44727966 & 0.50151819 & -0.89185131 \\
\hline 47.000000 & 0.0089409533 & 0.099328230 & 0.090014222 \\
\hline 48.000000 & 0.059105949 & 0.40382138 & 0.14636657 \\
\hline 49.000000 & -0.11102314 & 0.29529118 & -0.37597852 \\
\hline 50.000000 & 0.014490905 & 0.14063627 & 0.10303818 \\
\hline 51.000000 & -0.47961259 & 0.14530950 & -3.3006280 \\
\hline 52.000000 & -0.23067845 & 0.16161644 & -1.4273205 \\
\hline 53.000000 & -0.24620299 & 0.28543998 & -0.86253857 \\
\hline 54.000000 & 0.29828128 & 0.27734488 & 1.0754887 \\
\hline 55.000000 & 0.25499472 & 0.34844218 & 0.73181359 \\
\hline 56.000000 & 0.37743964 & 0.33618650 & 1.1227091 \\
\hline 57.000000 & -0.047243788 & 0.23605785 & -0.20013648 \\
\hline 58.000000 & 0.15673422 & 0.20099537 & 0.77979019 \\
\hline 59.000000 & 0.18558066 & 0.10199794 & 1.8194549 \\
\hline 60.000000 & 0.10235247 & 0.14819642 & 0.69065410 \\
\hline 61.000000 & 0.17890962 & 0.12127141 & 1.4752828 \\
\hline 62.000000 & -0.016260203 & 0.10541628 & -0.15424755 \\
\hline 63.000000 & -0.18879075 & 0.19789220 & -0.95400806 \\
\hline 64.000000 & 0.26687747 & 0.17658881 & 1.5112932 \\
\hline 65.000000 & 0.31499970 & 0.094252037 & 3.3420997 \\
\hline 66.000000 & 0.11014486 & 0.22966368 & 0.47959197 \\
\hline 67.000000 & 0.0018812198 & 0.13310066 & 0.014133812 \\
\hline 68.000000 & 0.48527576 & 0.24750401 & 1.9606784 \\
\hline 69.000000 & -0.0098414543 & 0.11718146 & -0.083984739 \\
\hline 70.000000 & 0.19451293 & 0.30091582 & 0.64640313 \\
\hline 71.000000 & 1.4327303 & 0.41452120 & 3.4563498 \\
\hline 72.000000 & -0.45772629 & 0.40374121 & -1.1337121 \\
\hline 73.000000 & 0.21491113 & 0.43808892 & 0.49056508 \\
\hline 74.000000 & -0.44844398 & 0.15925512 & -2.8158843 \\
\hline
\end{tabular}


75.000000
76.000000
77.000000
78.000000
79.000000
80.000000
81.000000
82.000000
83.000000
84.000000
85.000000
86.000000
87.000000
88.000000
89.000000
90.000000
91.000000
92.000000
93.000000
94.000000
95.000000
96.000000
97.000000
98.000000
99.000000
100.00000
101.00000
102.00000
103.00000
104.00000
105.00000
106.00000
107.00000
108.00000
0.081856955
0.11394735
0.088102520
0.12149919
0.32456787
0.26913798
0.10023025
0.30496102
0.18201120
0.13624505
0.20492695
0.11408818
0.22069971
0.13845442
0.25934561
0.45650941
0.13221584
0.39360210
1.0128672
0.21198478
0.29458275
0.11904203
0.52055199
0.18682612
0.17062301
0.23957276
0.23944760
0.30209837
0.10016371
0.16221794
0.25170775
0.29658160
0.27154336
0.18935566

\begin{tabular}{rrrr}
$\begin{array}{c}\text { parameters sigma } \\
\text { museum nr. }\end{array}$ & estimate & standard error & t-value \\
\hline 1.0000000 & 0.0000000 & 0.0000000 & 0.0000000 \\
2.0000000 & 0.50913240 & 0.16283597 & 3.1266581 \\
3.0000000 & 1.0641134 & 0.14419415 & 7.3797261 \\
4.0000000 & 0.17722483 & 0.11874984 & 1.4924217 \\
5.0000000 & 0.54747139 & 0.20678222 & 2.6475747 \\
6.0000000 & 0.62422174 & 0.062340942 & 10.013030 \\
7.0000000 & 1.1102955 & 0.27775430 & 3.9974017 \\
8.0000000 & 1.4923766 & 0.14872025 & 10.034791 \\
9.0000000 & 0.11550570 & 0.22025120 & 0.52442712 \\
10.000000 & 0.95452467 & 0.15821455 & 6.0331031 \\
11.000000 & 0.63231128 & 0.21701178 & 2.9137188 \\
12.000000 & 0.33481316 & 0.23475127 & 1.4262464 \\
13.000000 & 1.2488016 & 0.068481256 & 18.235670 \\
14.000000 & 0.68396667 & 0.10695459 & 6.3949260 \\
15.000000 & 0.10235019 & 0.28047556 & 0.36491659 \\
16.000000 & 0.11147883 & 0.22256035 & 0.50089259 \\
17.000000 & 1.0668251 & 0.20091599 & 5.3098067 \\
18.000000 & 0.96684914 & 0.091789815 & 10.533294 \\
19.000000 & 0.51182680 & 0.076761517 & 6.6677525 \\
20.000000 & 0.17414012 & 0.032382810 & 5.3775482 \\
21.000000 & 0.96713574 & 0.12351976 & 7.8298062 \\
22.000000 & 0.78678165 & 0.038320009 & 20.531875 \\
23.000000 & 0.92062881 & 0.088064443 & 10.454035 \\
24.000000 & 1.6760194 & 0.035385181 & 47.365009 \\
25.000000 & 0.42531654 & 0.17563087 & 2.4216503
\end{tabular}




\begin{tabular}{|c|c|c|c|}
\hline 26.000000 & 0.54740127 & 0.041349488 & 13.238405 \\
\hline 27.000000 & 1.3410389 & 0.13854837 & 9.6792112 \\
\hline 28.000000 & 1.3894153 & 0.078309670 & 17.742576 \\
\hline 29.000000 & 0.30039343 & 0.62917968 & 0.47743663 \\
\hline 30.000000 & 0.98142598 & 0.030331610 & 32.356541 \\
\hline 31.000000 & 0.31889551 & 0.11949795 & 2.6686274 \\
\hline 32.000000 & 0.73778103 & 0.11595784 & 6.3624939 \\
\hline 33.000000 & 0.33933517 & 0.19915959 & 1.7038354 \\
\hline 34.000000 & 0.37870227 & 0.051245610 & 7.3899456 \\
\hline 35.000000 & 0.57850631 & 0.18599363 & 3.1103556 \\
\hline 36.000000 & 0.50528421 & 0.098613877 & 5.1238651 \\
\hline 37.000000 & 1.0166463 & 0.29963357 & 3.3929652 \\
\hline 38.000000 & 0.70249865 & 0.14562352 & 4.8240741 \\
\hline 39.000000 & 1.3875521 & 0.047942283 & 28.942137 \\
\hline 40.000000 & 0.43488578 & 0.14454962 & 3.0085570 \\
\hline 41.000000 & 0.46617346 & 0.10273571 & 4.5375990 \\
\hline 42.000000 & 0.19566114 & 0.16877494 & 1.1593021 \\
\hline 43.000000 & 0.87286893 & 0.55509610 & 1.5724645 \\
\hline 44.000000 & 0.49958365 & 0.23000027 & 2.1721003 \\
\hline 45.000000 & 0.084703755 & 0.30022671 & 0.28213264 \\
\hline 46.000000 & 0.10425950 & 0.30797198 & 0.33853566 \\
\hline 47.000000 & 0.67006914 & 0.031093388 & 21.550213 \\
\hline 48.000000 & 1.0690107 & 0.15721089 & 6.7998515 \\
\hline 49.000000 & 0.15764746 & 0.21709905 & 0.72615452 \\
\hline 50.000000 & 0.40153594 & 0.059698820 & 6.7260281 \\
\hline 51.000000 & 0.97628020 & 0.038153385 & 25.588299 \\
\hline 52.000000 & 1.7035605 & 0.051862370 & 32.847717 \\
\hline 53.000000 & 0.78698219 & 0.076869406 & 10.237912 \\
\hline 54.000000 & 0.26066669 & 0.11954434 & 2.1805021 \\
\hline 55.000000 & 0.047880105 & 0.22715701 & 0.21077978 \\
\hline 56.000000 & 0.75542193 & 0.18156616 & 4.1605876 \\
\hline 57.000000 & 0.60510478 & 0.11436333 & 5.2910736 \\
\hline 58.000000 & 0.31094383 & 0.12711881 & 2.4460883 \\
\hline 59.000000 & 0.44829535 & 0.033255751 & 13.480235 \\
\hline 60.000000 & 0.49523292 & 0.068666491 & 7.2121484 \\
\hline 61.000000 & 0.048654390 & 0.088519548 & 0.54964571 \\
\hline 62.000000 & 0.016251725 & 0.069011719 & 0.23549225 \\
\hline 63.000000 & 0.45613156 & 0.11191526 & 4.0756868 \\
\hline 64.000000 & 1.2022386 & 0.050016322 & 24.036925 \\
\hline 65.000000 & 1.3983113 & 0.017650479 & 79.222289 \\
\hline 66.000000 & 0.96298944 & 0.077185166 & 12.476354 \\
\hline 67.000000 & 0.93389780 & 0.039816182 & 23.455232 \\
\hline 68.000000 & 0.88064952 & 0.066526323 & 13.237610 \\
\hline 69.000000 & 0.23351750 & 0.064910834 & 3.5975119 \\
\hline 70.000000 & 0.76432263 & 0.19452697 & 3.9291344 \\
\hline 71.000000 & 1.2936560 & 0.12960191 & 9.9817667 \\
\hline 72.000000 & 1.0748521 & 0.15898108 & 6.7608807 \\
\hline 73.000000 & 1.0440363 & 0.21171270 & 4.9313827 \\
\hline 74.000000 & 0.67946022 & 0.056895586 & 11.942231 \\
\hline 75.000000 & 0.83142307 & 0.013655491 & 60.885621 \\
\hline 76.000000 & 0.37191109 & 0.055630593 & 6.6853699 \\
\hline 77.000000 & 0.024649504 & 0.043479791 & 0.56691864 \\
\hline 78.000000 & 1.3371350 & 0.042644379 & 31.355481 \\
\hline 79.000000 & 0.23848305 & 0.23849063 & 0.99996822 \\
\hline 80.000000 & 0.10624134 & 0.18565484 & 0.57225191 \\
\hline 81.000000 & 0.036193143 & 0.054927599 & 0.65892454 \\
\hline 82.000000 & 0.37847151 & 0.27514114 & 1.3755541 \\
\hline 83.000000 & 0.64418919 & 0.064121151 & 10.046438 \\
\hline 84.000000 & 0.18023481 & 0.084735173 & 2.1270365 \\
\hline 85.000000 & 0.69514102 & 0.096855943 & 7.1770611 \\
\hline 86.000000 & 0.92241449 & 0.029085569 & 31.713819 \\
\hline 87.000000 & 0.13066420 & 0.10672217 & 1.2243398 \\
\hline 88.000000 & 1.0949652 & 0.046545796 & 23.52447 \\
\hline
\end{tabular}




$\begin{array}{lrrr}89.000000 & 0.46130152 & 0.18200184 & 2.5345981 \\ 90.000000 & 0.56367127 & 0.20341922 & 2.7709834 \\ 91.000000 & 0.33702290 & 0.071095271 & 4.7404405 \\ 92.000000 & 0.45301317 & 0.23457645 & 1.9311963 \\ 93.000000 & 0.81091898 & 0.31131919 & 2.6047831 \\ 94.000000 & 1.2510999 & 0.054400357 & 22.998010 \\ 95.000000 & 0.35529035 & 0.15943088 & 2.2284914 \\ 96.000000 & 0.86356185 & 0.044363856 & 19.465437 \\ 97.000000 & 0.52677891 & 0.37026352 & 1.4227135 \\ 98.000000 & 0.84725217 & 0.063355600 & 13.372964 \\ 99.000000 & 0.51756107 & 0.086406158 & 5.9898632 \\ 100.00000 & 0.94071901 & 0.081128420 & 11.595431 \\ 101.00000 & 0.82301822 & 0.10920187 & 7.5366680 \\ 102.00000 & 0.029893343 & 0.22800255 & 0.13110969 \\ 103.00000 & 0.86556156 & 0.023552130 & 36.750882 \\ 104.00000 & 0.72556431 & 0.066977741 & 10.832917 \\ 105.00000 & 1.3972101 & 0.10554138 & 13.238506 \\ 106.00000 & 0.73843172 & 0.17361492 & 4.2532734 \\ 107.00000 & 1.2396199 & 0.088196503 & 14.055204 \\ 108.00000 & 0.16756307 & 0.14227560 & 1.1777358\end{array}$

parameters (b0+a1) x 10 (distance decay)

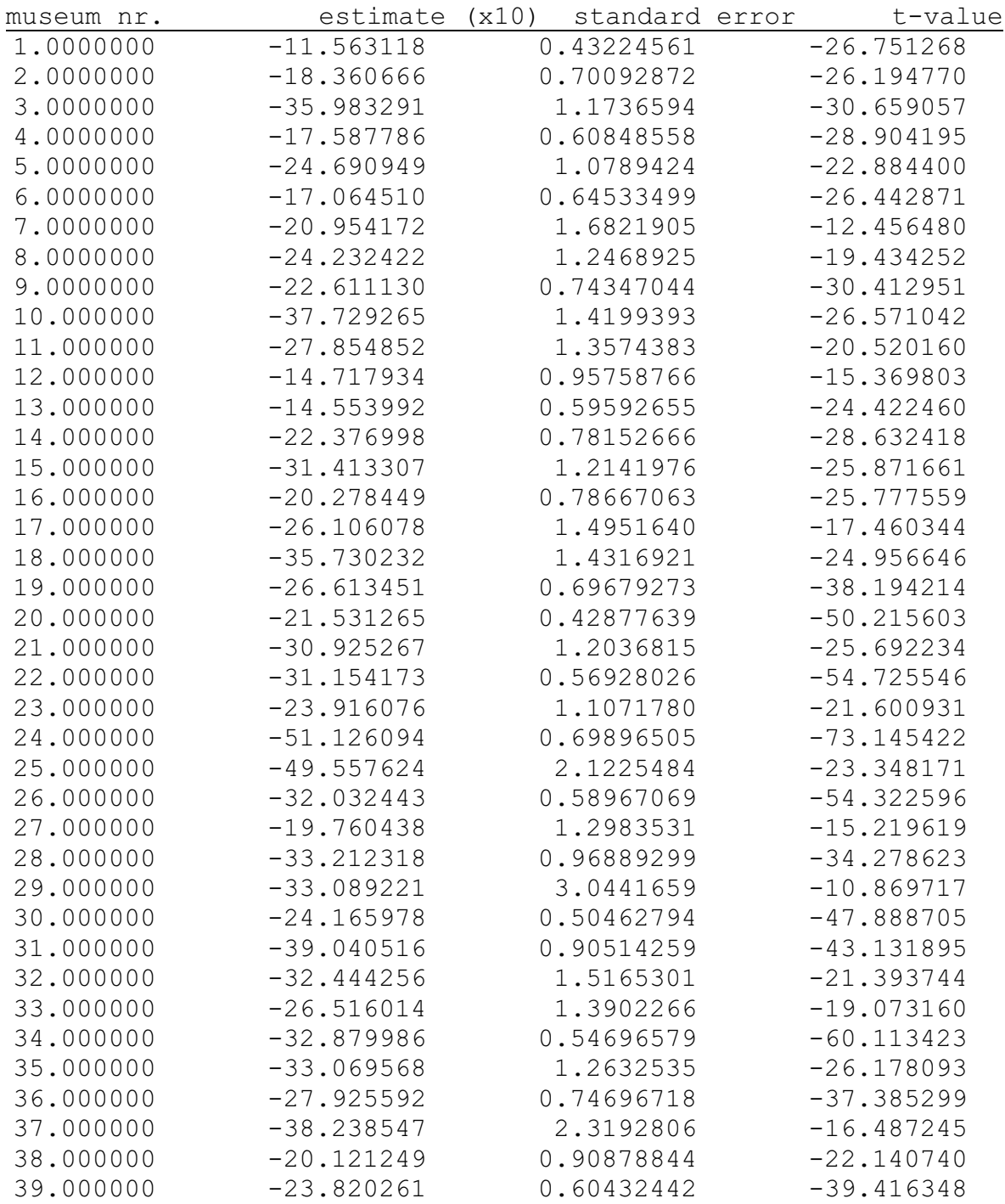




\begin{tabular}{|c|c|c|c|}
\hline 40.000000 & -40.208949 & 1.0719595 & -37.509764 \\
\hline 41.000000 & -41.402563 & 1.0738447 & -38.555448 \\
\hline 42.000000 & -19.876644 & 0.83379432 & -23.838786 \\
\hline 43.000000 & -25.299955 & 1.8529779 & -13.653673 \\
\hline 44.000000 & -17.709978 & 1.2624971 & -14.027737 \\
\hline 45.000000 & -19.698623 & 1.0025823 & -19.647886 \\
\hline 46.000000 & -12.815485 & 1.6563861 & -7.7370151 \\
\hline 47.000000 & -25.078868 & 0.52206279 & -48.038030 \\
\hline 48.000000 & -31.133197 & 1.4488846 & -21.487700 \\
\hline 49.000000 & -35.075100 & 1.9634896 & -17.863655 \\
\hline 50.000000 & -23.607898 & 0.60396545 & -39.088160 \\
\hline 51.000000 & -29.662706 & 0.79095758 & -37.502271 \\
\hline 52.000000 & -42.979644 & 0.82060402 & -52.375619 \\
\hline 53.000000 & -22.003429 & 1.0297402 & -21.367943 \\
\hline 54.000000 & -26.955450 & 0.91065777 & -29.599978 \\
\hline 55.000000 & -14.401985 & 1.3284682 & -10.841046 \\
\hline 56.000000 & -22.282569 & 1.6017754 & -13.911170 \\
\hline 57.000000 & -30.992495 & 1.0818884 & -28.646666 \\
\hline 58.000000 & -38.374284 & 0.83545919 & -45.931967 \\
\hline 59.000000 & -26.541491 & 0.49429863 & -53.695255 \\
\hline 60.000000 & -20.439248 & 0.62852338 & -32.519471 \\
\hline 61.000000 & -20.899428 & 0.54915067 & -38.057730 \\
\hline 62.000000 & -21.792987 & 0.49880901 & -43.690042 \\
\hline 63.000000 & -21.317707 & 0.78347936 & -27.209021 \\
\hline 64.000000 & -21.179561 & 0.75603756 & -28.013900 \\
\hline 65.000000 & -27.317250 & 0.45629617 & -59.867367 \\
\hline 66.000000 & -27.484449 & 1.0203162 & -26.937188 \\
\hline 67.000000 & -29.434860 & 0.58519199 & -50.299492 \\
\hline 68.000000 & -42.647856 & 1.2723698 & -33.518444 \\
\hline 69.000000 & -23.731468 & 0.56691820 & -41.860480 \\
\hline 70.000000 & -21.271603 & 1.0960216 & -19.408015 \\
\hline 71.000000 & -141.76362 & 6.9329623 & -20.447770 \\
\hline 72.000000 & -41.870554 & 2.3979299 & -17.461125 \\
\hline 73.000000 & -18.641174 & 2.0588717 & -9.0540729 \\
\hline 74.000000 & -35.157130 & 0.75512891 & -46.557786 \\
\hline 75.000000 & -24.858907 & 0.44211816 & -56.226839 \\
\hline 76.000000 & -23.543520 & 0.55752178 & -42.228878 \\
\hline 77.000000 & -19.485214 & 0.44492282 & -43.794593 \\
\hline 78.000000 & -17.378892 & 0.61041046 & -28.470829 \\
\hline 79.000000 & -25.539729 & 1.6522141 & -15.457881 \\
\hline 80.000000 & -21.523314 & 0.73365806 & -29.336983 \\
\hline 81.000000 & -18.959903 & 0.46790442 & -40.520889 \\
\hline 82.000000 & -21.808482 & 1.1710613 & -18.622836 \\
\hline 83.000000 & -27.038130 & 0.72999722 & -37.038675 \\
\hline 84.000000 & -24.932366 & 0.61868178 & -40.299177 \\
\hline 85.000000 & -27.133332 & 1.0090168 & -26.890861 \\
\hline 86.000000 & -24.696617 & 0.54750516 & -45.107551 \\
\hline 87.000000 & -33.210768 & 0.90559654 & -36.672808 \\
\hline 88.000000 & -27.604460 & 0.58821477 & -46.929219 \\
\hline 89.000000 & -26.385021 & 1.0719122 & -24.614908 \\
\hline 90.000000 & -25.315284 & 1.2145732 & -20.842946 \\
\hline 91.000000 & -21.844270 & 0.59832026 & -36.509327 \\
\hline 92.000000 & -39.707949 & 1.5812647 & -25.111513 \\
\hline 93.000000 & -72.038138 & 3.8913535 & -18.512360 \\
\hline 94.000000 & -47.890760 & 0.95953326 & -49.910474 \\
\hline 95.000000 & -20.469498 & 0.97750315 & -20.940595 \\
\hline 96.000000 & -26.610077 & 0.53467301 & -49.768879 \\
\hline 97.000000 & -31.901669 & 2.1721860 & -14.686436 \\
\hline 98.000000 & -27.067334 & 0.70083770 & -38.621401 \\
\hline 99.000000 & -24.632167 & 0.75181870 & -32.763441 \\
\hline 100.00000 & -19.690539 & 0.87872503 & -22.408078 \\
\hline 101.00000 & -39.887792 & 1.1115999 & -35.883226 \\
\hline 102.00000 & -29.603342 & 1.1919331 & -24.836412 \\
\hline
\end{tabular}




$\begin{array}{llrl}103.00000 & -29.546266 & 0.50528175 & -58.474833 \\ 104.00000 & -26.690295 & 0.71369926 & -37.397117 \\ 105.00000 & -30.418546 & 1.0253252 & -29.667218 \\ 106.00000 & -26.223221 & 1.3457113 & -19.486513 \\ 107.00000 & -42.171570 & 1.2510330 & -33.709398 \\ 108.00000 & -30.790286 & 0.92008157 & -33.464735\end{array}$

\begin{tabular}{|c|c|c|c|}
\hline group nr. & estimate & standard error & t-value \\
\hline 1.0000000 & 0.67635936 & 0.010917121 & 61.954004 \\
\hline 2.0000000 & 0.021055520 & 0.019038054 & 1.1059702 \\
\hline 3.0000000 & 1.0275297 & 0.027001252 & 38.054892 \\
\hline 4.0000000 & 0.60997800 & 0.025915708 & 23.537000 \\
\hline 5.0000000 & 0.99243733 & 0.027285781 & 36.371960 \\
\hline 6.0000000 & 0.55090473 & 0.042379699 & 12.999260 \\
\hline
\end{tabular}

parameter b1 (distance decay $x$ income/1000) estimate $(x 10)$ standard error t-value

$\begin{array}{lcc}-0.019657394 & 0.32293854 & -0.060870389\end{array}$

parameter sigma0 x10 (distance decay * random variable)

\begin{tabular}{crr} 
estimate $(\mathrm{x} 10)$ & standard error & t-value \\
\hline-10.930111 & 0.096890008 & -112.80947
\end{tabular}

